\title{
Smart Mobility: Contradictions in Value Co-Creation
}

\author{
Thomas Schulz $^{1,2}$ (D) $\cdot$ Heiko Gewald ${ }^{3} \cdot$ Markus Böhm $^{4} \cdot$ Helmut Krcmar $^{5}$
}

(C) The Author(s) 2020

\begin{abstract}
Technical progress is disrupting the mobility sector. New door-to-door (D2D) mobility integrators promise to offer smart mobility by packaging together different mobility services such as car-sharing and public transport. However, mobility providers up to now have rarely entered into value co-creation relationships. As a result, citizens are offered mobility that cannot be considered truly smart. Although value co-creation has been the subject of numerous studies taking the service-dominant logic perspective, this research has often lacked empirical evidence. To close this gap, we conceptualize value co-creation between mobility providers and a D2D mobility integrator by applying Activity Theory. Based on a qualitative study in the German mobility sector, we identify several inhibitors of value co-creation from the viewpoint of mobility providers. In addition, we show how these inhibitors serve as triggers for adaptations, ultimately leading to the formation of a value co-creation relationship.
\end{abstract}

Keywords Activity theory $\cdot$ Service-dominant logic $\cdot$ Smart mobility $\cdot$ Value co-creation

\section{Introduction}

Creating a new mobility paradigm is of one of the grand challenges of the twenty-first century. Cities around the world are confronted with urgent problems such as traffic congestion, parking problems as well as noise and air pollution (Willing et al. 2017a, 2017b; Benevolo et al. 2016; Gupta et al. 2019; Schreieck et al. 2018). One of the main reasons for this is the popularity of the use of private cars. For example, motorized private transport accounted for approximately $75 \%$ of the total transport volume in Germany in 2017 (Follmer and Gruschwitz 2019). The situation could deteriorate even further in the future through urbanization. One forecast predicts that the share of the worldwide population living in cities will increase from 50\% in 2015 to $66 \%$ by

Thomas Schulz

Thomas.Schulz@hs-neu-ulm.de

Heiko Gewald

Heiko.Gewald@hs-neu-ulm.de

Markus Böhm

Markus.Boehm@in.tum.de

Helmut Krcmar

Krcmar@in.tum.de

1 Neu-Ulm University of Applied Sciences, Center for Research on Service Sciences (CROSS), Wileystraße 1, 89231,

Neu-Ulm, Germany
2050 (United Nations Department of Economic and Social Affairs 2015).

Despite its possible contribution to alleviating the problems, the share of mobility provided by public transport is often small. Inconveniences such as a lack of door-to-door (D2D) transport and poor information quality regarding transport services have been identified as key factors of non-usage (Beirão and Cabral 2007). In particular, the availability of the "right information at the right time" is considered to be important to facilitate sustainable behavioral changes in the broader public (Watson et al. 2011, p. 59). Several authors argue that information systems (IS) researchers can and need to contribute to the grand challenge of environmental sustainability (Watson et al. 2010; Elliot 2011; Hasan et al. 2017; Gupta et al. 2019; Akande et al. 2019; Gupta et al. 2018).

2 Technical University of Munich, Chair for Information Systems, Boltzmannstraße 3, 85748 Garching bei München, Germany

3 Neu-Ulm University of Applied Sciences, Center for Research on Service Sciences (CROSS), Wileystraße 1, 89231, Neu-Ulm, Germany

4 Technical University of Munich, Chair for Information Systems, Boltzmannstraße 3, 85748 Garching bei München, Germany

5 Technical University of Munich, Chair for Information Systems, Boltzmannstraße 3, 85748 Garching bei München, Germany 
The proliferation of information technology (IT) such as smartphones has simplified potential customers' access to information. Apart from the ever increasing availability of information, technical progress is increasingly changing the provision of services (Gretzel et al. 2015; Dai et al. 2018). Large amounts of data (big data) are generated and analyzed from a growing number of sources, such as smartphones, business transactions, sensors installed in vehicles (e.g., busses, cars, trains), and social media posts (Pappas et al. 2018). In this context, Mikalef et al. (2020) also denotes data "as one of the most valuable organizational resources".

The rise of big data and big data analytics lead to the emergence of new companies with new business models. Among other things, big data analytics is expected to result in new possibilities to satisfy customers' needs through better services, provide companies with an opportunity to develop a competitive advantage and increase business value, but also increase social value by contributing to the development of sustainable societies, for example, with regard to environmental sustainability (Pappas et al. 2018; Gupta et al. 2018; Mikalef et al. 2020; Klievink et al. 2017; Willing et al. 2017a; Popovič et al. 2018; Côrte-Real et al. 2020). However, to date, there is little research that focuses on the societal impact of big data and big data analytics (Pappas et al. 2018; Gupta et al. 2018).

Relying on big data and big data analytics, emerging D2D mobility integrators (like Moovel, Qixxit, etc.) strive to provide smart mobility from a defined starting-point to a defined end-point that is characterized by individual, context-aware, and dynamic bundling of mobility services such as bike-sharing, car-sharing and public transport (Schulz et al. 2018). Such smart mobility gives customers access to information about unexpected delays or cancellations, automatically updating their trip options accordingly. Since each of these mobility services is available individually on the market, this is a socalled 'component mobility service'.

The different mobility providers form a service ecosystem (Lusch and Nambisan 2015), and a D2D mobility integrator acting as keystone organization can be considered a 'smart integrator' (Schulz et al. 2018). The overall aim of the service ecosystem can be seen to improve world-wide quality of life by moving beyond addressing customer needs atomistically (Alt et al. 2019), and thus shifting human behavior towards non-private car-based mobility. According to Pappas et al. (2018), such service ecosystems that rely on vast amount of data of a number of actors can also be referred to as big data and business analytics ecosystems in which actors do not act in isolation. Hence, it is important to understand each of the actors, their data, and how they interact.

In order to offer customers smart mobility, mobility providers must provide various data about their mobility service, such as timetables, fares, passenger counts and vehicle positions (Ahlers et al. 2018). Unfortunately, to date, D2D mobility integrators in the German-speaking regions often struggle to get access to the data - specifically from public transport companies (Willing et al. 2017a, 2017b; Albrecht and Ehmke 2016). In addition, even if they get access, the quality of the data is often not good enough (e.g., only static timetables). These results are consistent with other studies (Klievink et al. 2017; Okwechime et al. 2018) that analyze the use of big data and big data analytics in different public organizations, and identify a need to catch up with private companies. Poor data quality makes it difficult to unlock the value of big data analytics (Côrte-Real et al. 2020). Thus, in order to be able to offer smart mobility, it is necessary to increase both the quantity and the quality of available data. But why are especially public transport companies not able or willing to co-create value?

The service-dominant (S-D) logic literature conceptualizes resource integration and service exchange as the building blocks of value co-creation (Vargo and Lusch 2017). From a mobility provider's point of view, the provision of a component mobility service that consists of a transport service and possibly supplementary services (e.g., the provision of realtime timetable information and of mobile tickets) on which we focus here, can generally be defined as "the application of resources for the benefit of others" (Vargo and Lusch 2017, p. 48). However, most studies adopting the S-D logic perspective are conceptual in nature and do not provide empirical evidence (e.g., Storbacka et al. 2016; Vargo and Lusch 2004, 2017). In addition, there are only few studies in the IS (e.g., Turetken et al. 2019; Schulz and Überle 2018; Gilsing et al. 2018; Hein et al. 2018; Schulz et al. 2020) and other scientific fields (e.g., Alexander and Jaakkola 2011; Echeverri and Skålén 2011; Gebauer et al. 2010; Pulkkinen et al. 2019; Yin et al. 2019) that have examined value co-creation in a mobility context. As Breidbach and Maglio (2016, p. 74) summarized: "we know very little about how economic actors engage in the process of value co-creation in traditional, colocated contexts [...], let alone in technology-enabled ones".

To close this gap, Vargo and Lusch (2017, p. 46) recommend the use of theories outside of marketing to further develop the S-D logic perspective by creating "more midrange theoretical frameworks and concepts of service exchange, resource integration, [and] value cocreation". In response to this call, we draw on Activity Theory (AT) (Kuutti 1996; Engeström 1987) to examine the lack of value co-creation by analyzing the resource integration and service exchange actions that underlie the value co-creation activity of mobility providers (Vargo and Lusch 2017; Kuutti 1996). Building on the concept of contradictions (Engeström 1987), which become visible in form of double binds, critical conflicts, conflicts, and dilemmas (Engeström and Sannino 2011), and on the concept of congruencies (Allen et al. 2013), we identify the inhibitors to value co-creation and derive recommendations on how to solve them. Thus, we pose the research 
question: How to increase value co-creation (1.e., resource integration and service exchange) by mobility providers to realize smart mobility?

We conceptualize value co-creation from an interacting activity systems perspective. Based on this theoretical frame, we assess the inhibitors inherent in the activity systems. Our considerations are guided by the work of Schulz et al. (2020), who emphasize the benefits of adopting an activity system thinking for analyzing value co-creation, but without drawing on interacting activity systems as the unit of analysis (Engeström 2001) and the concepts of contradictions and congruencies (Allen et al. 2013; Engeström 1987).

We drew on interviews with experts from twelve German transport and tariff associations (TTAs), the regional representatives of public transport companies, to inform out conceptualization and test its applicability. One of the TTAs had recently signed a letter of intent with a D2D mobility integrator to join its service ecosystem. We find that in particular, the goal to provide smart local mobility in the future themselves, impedes the realization of value co-creation, and thus of smart mobility. Furthermore, our results show how these inhibitors serve as triggers for adaptations, ultimately leading to the formation of a value co-creation relationship.

The article is structured as follows. First, we present current developments in the fields of S-D logic perspective and AT. Then we outline our AT-based S-D logic perspective on value co-creation. Next, we elucidate the context of our study and our methodology. Finally, we present our results and discuss the implications of our study and its limitations and avenues for future research. The article closes with a conclusion.

\section{Theoretical Foundation}

\subsection{Service-Dominant Logic Perspective}

The cooperation of several actors for service provision can be analyzed by adopting the service-dominant (S-D) logic perspective. The S-D logic perspective was originally introduced to marketing (Vargo and Lusch 2004), but in the meantime is established in numerous scientific fields, including business economics (e.g., Koskela-Huotari et al. 2016; Storbacka et al. 2016) and IS (e.g., Hein et al. 2019; Giesbrecht et al. 2017; Winkler and Wulf 2019; Rahman et al. 2019; see Brust et al. 2017 for an overview). Some of the studies focused on value co-creation in a digital (e.g., Turetken et al. 2019; Schulz and Überle 2018; Gilsing et al. 2018; Hein et al. 2018; Pulkkinen et al. 2019; Schulz et al. 2020) and a non-digital (e.g., Alexander and Jaakkola 2011; Echeverri and Skålén 2011; Gebauer et al. 2010) mobility context.

The intended change in focus among citizens away from the purchase of private cars towards the use of mobility services represents a shift from the goods-dominant (G-D) logic to the S-D logic (Schulz and Überle 2018). This change can be supported by technological progress, which has fostered the emergence of IT-based service ecosystems, such as in the case of ride- and car-sharing. The S-D logic perspective is based on three concepts: (1) the service ecosystem, (2) the service platform, and (3) value co-creation (Hein et al. 2018; Lusch and Nambisan 2015).

A service ecosystem is an actor-to-actor network and can be defined as "a relatively self-contained, self-adjusting system of mostly loosely coupled social and economic (resourceintegrating) actors connected by shared institutional logics and mutual value creation through service exchange" (Lusch and Nambisan 2015, p. 161). Schulz and Überle (2018) specified the actors involved in the service ecosystem of a D2D mobility integrator. The actors include different mobility providers, such as public transport, car-, bike-, and ride-sharing companies, government agencies (national government, municipalities, etc.) and customers. The shared institutional logics (or synonymously the institutional arrangements) (Vargo and Lusch 2017; Lusch and Nambisan 2015), which represent rules, norms, and beliefs, govern the actors and their service exchange within and between service ecosystems (Vargo and Lusch 2017). However, institutional arrangements not only enable service exchange, they can also constrain it (Schulz et al. 2020). In this vein, Koskela-Huotari et al. (2016, p. 2964) highlighted that "breaking, making, and maintaining" institutional arrangements creates opportunities for a new form of value co-creation.

A service platform represents "a modular structure that consists of tangible and intangible components (resources) and facilitates the interaction of actors and resources (or resource bundles)" (Lusch and Nambisan 2015, p. 162). By using a service platform, actors can make their service exchange more effective and efficient (Lusch and Nambisan 2015; Hein et al. 2018). In the present case, the smartphone app provided by a D2D mobility integrator serves as a service platform. The smartphone app recommends different bundles of mobility services, including automatic adjustments in case of delays and cancellations, for a door-to-door trip. This allows customers to reduce their search costs and cognitive effort in the run-up, as well as during the trip.

Technological breakthroughs (like the availability of sensors and smartphones) and changes that occur in an industry logic, as it is currently the case in the mobility sector, offer new opportunities for value co-creation (Payne et al. 2008). Value co-creation is defined as resource integration and service exchange by the actors of a service ecosystem (Vargo and Lusch 2017). Customers are also involved in value cocreation (Vargo et al. 2008). For example, they can use the smartphone app to provide information on how crowded the bus or train is at the moment (Nunes et al. 2014). While the G$\mathrm{D}$ logic is based on the assumption that the value of goods, such as cars, is determined by the producers (value-in- 
exchange), one of the central assumptions of S-D logic is its principle of value-in-use (Vargo and Lusch 2004), or more specifically value-in-context (Vargo and Lusch 2017; Vargo et al. 2008), which means "that value is fundamentally derived and determined in use - the integration and application of resources [i.e. service (Vargo and Lusch 2017)] in a specific context - rather than in exchange - embedded in firm output and captured by price" (Vargo et al. 2008, p. 145).

The value that an individual actor of a service ecosystem can realize through value co-creation can be very different. For a non-digital context, Alexander and Jaakkola (2011) have defined the value that arises for customers as improved station environments and reduction in anti-social behavior. In contrast, the value generated for companies, for instance, is an increase in passenger volume and a differentiation from competitive offers (Gebauer et al. 2010). For a digital context, Gilsing et al. (2018, p. 2) explained that customers "look at the value (e.g., the flexibility and ease-of-use) offered by car sharing applications". In the case of the smartphone apps provided by the D2D mobility integrators, the value for customers could be economic in nature, if the bundle of mobility services with the cheapest price is recommended, or social, if the bundle with the least air pollution is identified. For the mobility providers, such as public transport companies, value is generated in form of higher customer satisfaction by offering door-to-door mobility and higher customer loyalty for example.

Notwithstanding the fact that the S-D logic perspective is established in many scientific fields and is accepted for the analysis of value co-creation in service ecosystems, there are some limitations that make its application and especially the generation of practical implications difficult. Currently, the S$\mathrm{D}$ logic perspective is on a meta-theoretical level (Vargo and Lusch 2017), which means that value co-creation is difficult to observe empirically. As a result, there are numerous conceptual studies, on the basis of which it is difficult to derive practical implications. A remedy can be provided by the use of actor engagement as microfoundation for value co-creation, which is defined as "both the actor's disposition to engage, and the activity of engaging in an interactive process of resource integration within a service ecosystem" (Storbacka et al. 2016, p. 3008).

To further develop the S-D logic perspective, Vargo and Lusch (2017, p. 46) recommended the development of "more midrange theoretical frameworks and concepts of service exchange, resource integration, value cocreation, value determination, and institutions/ecosystems. These midrange theories can be partially informed by theories outside of marketing". Corresponding future studies should focus in particular on ITenabled value co-creation, since knowledge about it is very limited (Breidbach and Maglio 2016).

In the following section, we introduce AT, which can help in further development of the S-D logic perspective. Three specific characteristics of AT make it advantageous for complementation: (1) AT assumes that several actors are involved in an activity. This assumption fits the concept of service ecosystem stemming from the S-D logic perspective; (2) the activity system, which constitutes the basic unit of analysis of AT, includes the instruments element. Thus, IT, such as a service platform (i.e. a smartphone app) that is used in a service ecosystem, can be taken into account; and (3) the three levels of an activity (activity, actions and operations) allow the use of actor engagement as a microfoundation for value cocreation.

\subsection{Activity Theory}

Activity Theory (AT) is a "philosophical and crossdisciplinary framework for studying different forms of human practices" (Kuutti 1996, p. 25). Scholars in numerous research fields, such as IS (Hasan et al. 2017; Allen et al. 2013; Karanasios and Allen 2013, 2014; Sun 2020; Slavova and Karanasios 2018; Malaurent and Karanasios 2020; Dennehy and Conboy 2020; Schulz et al. 2020, etc.), management sciences (e.g., Jarzabkowski 2003), organizational sciences (e.g., Engeström 2000a; Blackler et al. 2000), education (Engeström 2001; Dionne and Bourdon 2018, etc.) and research on human-computer interaction (Kuutti 1996; Kaptelinin 1996, etc.) view AT as an important theory that can lead to novel theoretical and practical contributions. AT has already been used to investigate and redesign work activities of individuals and teams (Engeström 2000b). Numerous scholars (Karlsson and Wistrand 2006; Korpela et al. 2004; Zott and Amit 2009) have argued that entire companies can also be viewed as activity systems. Expanding the activity system thinking beyond a company's boundaries can enrich the S-D logic perspective (Schulz et al. 2020).

The basic assumption of AT is that the activity of a subject (a person or a collective) is always directed towards a tangible or intangible object in order to transform it and to subsequently achieve a specific outcome (Engeström 1987; Leont'ev 1978). In other words, the object is "the 'raw material' or 'problem space"" (Engeström 1993, p. 67). An activity is a longer-term formation and "consist[s] of actions or chains of actions, which in turn consist of operations" (Kuutti 1996, p. 30). An activity is based on an overall motive (in our case the realization of value co-creation), while conscious actions are goal-oriented. Actions, in turn, consist of several nonconscious operations that represent well-defined routines. The borders between these hierarchical levels of an activity are blurred and movements are possible (Kuutti 1996). For example, "an activity can lose its motive and become an action, and an action can become an operation when the goals changes" (Davydov et al. 1983, p. 36). Due to this circumstance, it is not possible to provide a general classification of what an activity (or action or operation) is (Kuutti 1996). 
In line with the S-D logic perspective (Vargo and Lusch 2017), the value co-creation of each actor can be understood as an activity consisting of two successive actions: resource integration and service exchange. In the case of a public transport company (i.e. subject), the two actions are carried out with the goal of transporting customers between stations (i.e. object). In contrast, the goal of a D2D mobility integrator is the provision of smart mobility. Based on the assumption that actor engagement is a microfoundation of value co-creation, "both the actor's [for instance, the public transport company's] disposition to engage, and the activity of engaging" (Storbacka et al. 2016, p. 3008) in the two actions are in the focus of interest.

Human activities are always mediated by one or more tangible and intangible instruments (in our case a ticketing machine, vehicle, etc.) (Engeström 1987; Leont'ev 1978; Vygotsky 1978) that enable the subject to transform the object and to obtain a specific outcome more efficiently (Blackler et al. 2000; Allen et al. 2013). Hence, instruments are artefacts that empower a subject through the experiences and skills collected over time. Nevertheless, an instrument can also limit the possible actions of a subject (Kuutti 1996). The relationship between subject, object, and instrument - also denoted as first generation of AT (Engeström 2001) - is illustrated in the form of a triangle and constitutes the first part of the activity system (Fig. 1).

Engeström (1987) extended the basic triangle by adding the community to the activity system, which also mediates the relationship between the subject and the object. In addition, the rules and the division of labor are added, creating further mediating relationships (second generation of AT). The rules cover explicit and implicit norms, conventions, and social relations (e.g. transport guidelines, pricing schemes). The explicit and implicit organization within a collective activity is captured by the division of labor (Kuutti 1996).

Last but not least, the third generation of AT focuses on the analysis of two or more interacting activity systems. Figure 1 shows how "the object moves from an initial state of unreflected, situationally given 'raw material' (object 1; $[\ldots])$ to a collectively meaningful object constructed by the activity system (object $2,[\ldots]$ ), and to a potentially shared or jointly constructed object (object 3; [...])" (Engeström 2001, p. 136) for the minimal case of two interacting activity systems. The third generation of AT can be summarized by five principles, which are shown in Table 1.

Since the principle 4 is particularly important for the theoretical foundation of the present study, some further explanations on contradictions are provided. Contradictions oppose "the overall motive of the system, the aim or purpose that subjects within the system are individually or collectively striving toward" (Allen et al. 2013, p. 840), but cannot be observed directly; they only manifest themselves as double binds, critical conflicts, conflicts, and dilemmas (Engeström and Sannino 2011).

Engeström (1987) distinguished four levels of contradictions, which are located on different positions of the activity system (see Fig. 1): (1) Primary contradictions can arise within each element of the activity system. An example is the lacking interoperability of IT systems in the case of the instruments element. (2) Secondary contradictions exist between the elements of the activity system. For instance, strong cost pressure (i.e. rules) may cause that advanced IT, such as a mobile ticketing solution and sensors that are necessary for the provision of real-time timetable information, are not integrated into the activity system of a public transport company. (3) Tertiary contradictions are located between the object of an activity and the object of a culturally more advanced form of the same activity. Instead of offering a transport service that is based on a fixed timetable, a public transport company can, for instance, provide transport on demand. This type of contradiction is not relevant to the current study. (4) Quaternary contradictions occur between interacting activity systems. For example, such a contradiction occurs between the two objects when the component mobility service provided by a public transport company, for example due to the lacking integration of real-time timetable information, prevents the provision of smart mobility by a D2D mobility integrator.

Through a process of feedback and action, contradictions can be transformed into congruencies, which reflect the
Fig. 1 Two Interacting Activity Systems as Minimal Model for the Third Generation of AT (based on Engeström 2001, p. 136 and Engeström 1987)

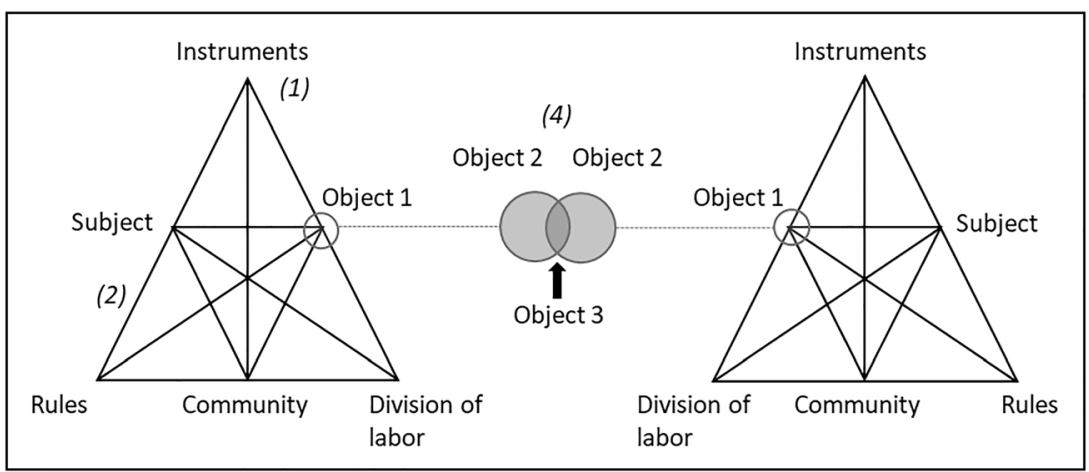


"stabilizing forces within activity systems" (Allen et al. 2013, p. 841). A congruence between the elements of an activity system arises when, for example, contradictions trigger the introduction of new IT, which in contrast to the old IT, fits the established rules and division of labor. In other words, congruencies influence the decision whether, and in what way, the actors of an activity system adopt IT (Allen et al. 2013).

Due to the concepts of contradictions and of congruencies, we believe that AT can constructively complement the S-D logic perspective. According to the latter, "breaking, making, and maintaining the institutionalized rules of resource integration" established in a service ecosystem offers actors the opportunity to realize a novel form of value co-creation (Koskela-Huotari et al. 2016, p. 2964). AT focusing on interacting activity systems and on the transformation of contradictions into congruencies can provide a deeper theoretical foundation.

\section{Value Co-Creation in Cross-Company Activity Systems}

AT offers a useful theoretical lens through which the lack of value co-creation (defined as activity) of mobility providers can be analyzed in the context of D2D mobility integrators. First, we can further specify the elements of the interacting activity systems (i.e. subject, object, instruments, rules, community, and division of labor) (Engeström 2001), which must be taken into account in the analysis of value co-creation. Second, AT explicitly conceptualizes IT as a mediating instrument within an activity (Kuutti 1996) and thus makes it possible to focus on IT-enabled value co-creation. Finally, a deeper understanding of AT - in contrast to Schulz et al. (2020) - to include an application of both its concepts of contradictions (Engeström 1987) and congruencies (Allen et al. 2013) might help us identify solutions to inhibitors (which are the manifestations of contradictions) for value co-creation.
Table 1 The Principles of the Third Generation of AT

(Engeström 2001, p. 136)

\begin{tabular}{|c|c|}
\hline Principle & Explanation \\
\hline $\begin{array}{l}\text { 1. Activity system as the prime unit of } \\
\text { analysis }\end{array}$ & $\begin{array}{l}\text { "A collective, artefact-mediated and object-oriented activity } \\
\text { system, seen in its network relations to other activity systems, is } \\
\text { taken as the prime unit of analysis. Goal-directed individual and } \\
\text { group actions, as well as automatic operations, are relatively } \\
\text { independent but subordinate units of analysis". }\end{array}$ \\
\hline 2. Multi-voicedness of an activity system & $\begin{array}{l}\text { "An activity system is always a community of multiple points of } \\
\text { view, traditions and interests. The division of labor in an activity } \\
\text { creates different positions for the participants, the participants } \\
\text { carry their own diverse histories, and the activity system itself } \\
\text { carries multiple layers and strands of history engraved in its } \\
\text { artifacts, rules and conventions. The multi-voicedness is multi- } \\
\text { plied in networks of interacting activity systems. It is a source of } \\
\text { trouble and a source of innovation". }\end{array}$ \\
\hline 3. Historicity of an activity system & $\begin{array}{l}\text { "Activity systems take shape and get transformed over lengthy } \\
\text { periods of time. Their problems and potentials can only be } \\
\text { understood against their own history. History itself needs to be } \\
\text { studied as local history of the activity and its objects, and as } \\
\text { history of the theoretical ideas and tools that have shaped the } \\
\text { activity". }\end{array}$ \\
\hline $\begin{array}{l}\text { 4. Central role of contradictions as sources } \\
\text { of change and development }\end{array}$ & $\begin{array}{l}\text { "Contradictions are historically accumulating structural tensions } \\
\text { within and between activity systems. [...]. When an activity } \\
\text { system adopts a new element from the outside (for example, a } \\
\text { new technology or a new object), it often leads to an aggravated } \\
\text { secondary contradiction where some old element (for example, } \\
\text { the rules or the division of labor) collides with the new one. } \\
\text { Such contradictions generate disturbances and conflicts, but } \\
\text { also innovative attempts to change the activity". }\end{array}$ \\
\hline 5. Possibility of expansive transformations & $\begin{array}{l}\text { "Activity systems move through relatively long cycles of } \\
\text { qualitative transformations. As the contradictions of an activity } \\
\text { system are aggravated, some individual participants begin to } \\
\text { question and deviate from its established norms. In some cases, } \\
\text { this escalates into collaborative envisioning and a deliberate } \\
\text { collective change effort. An expansive transformation is } \\
\text { accomplished when the object and motive of the activity are } \\
\text { reconceptualized to embrace a radically wider horizon of } \\
\text { possibilities than in the previous mode of the activity". }\end{array}$ \\
\hline
\end{tabular}


In the following, we discuss our AT-based S-D logic perspective on value co-creation. In order to enable a more general theory development, we adopt a broad perspective and do not limit ourselves to the mobility sector. We use the term service provider to describe a company that is offering an independent and freely available service on the market (i.e. a component service). On the other hand, a smart integrator and the service providers from its service ecosystem provide component service packages so that the customer receives a holistic solution.

We first describe the activity system of a service provider (AS-SP) as illustrated in Fig. 2 on the left. In this case, the value co-creation activity of a service provider (i.e. subject) is directed to the provision of a specific service like a financial advisory, an education service, or a healthcare service (i.e. object) to satisfy a customer need. A number of different mediating instruments, some of which represent a service platform in terms of the S-D logic perspective (Lusch and Nambisan 2015), can be deployed during this activity. For example, a bank can introduce tablets to improve the faceto-face advisory process (Nueesch et al. 2014) or a customer (i.e. community) can use a video that is provided in an electronic learning system (Zhang et al. 2006). In addition, there are rules such as medical confidentiality (Kottow 1986) that govern the relationship between the service provider and the customer. Due to the fact that a customer in addition to the service provider performs a value co-creation activity (Vargo and Lusch 2004), a division of labor also exists. For example, it is necessary that the customer provides her/his requirements (e.g. timeline) at the beginning of a service (Nueesch et al. 2014).

A complex customer need can however not be satisfied by a single service provider (Alt et al. 2019). In the traditional case, due to a service provider's focus on its component service, customer support for the creation of a service package is not possible. According to Alt et al. (2019), this applies in particular to the aforementioned sectors. A customer therefore has to combine a number of component services manually to receive a holistic solution (i.e. outcome). Figure 2 depicts the component services provided by three exemplary service providers as object of three staggered activity system triangles.

The activity system of a smart integrator (AS-SI) is illustrated in Fig. 2 on the right. We focus on its value co-creation activity, which includes, among others, a customer and service providers (i.e. community). The activity is directed towards the transformation of different component services in a smart service package (i.e. object) to better satisfy an existing need (i.e. outcome). Thus, the object of each AS-SP transforms into the object of AS-SI. The more or less standardized component services (e.g. public transport, car-sharing service) of individual service providers are now no longer of immediate concern. Instead, we concentrate on the realization of a smart service package. For this, a customer must take a more active role in the service process. For example, s/he must continuously integrate information about her/his changing context (i.e. division of labor). In addition, a smart integrator relies on advanced IT such as an algorithm for the automatic packaging of component services (i.e. instrument) to offer a smart service package. A particular characteristic of a smart service package is its strong dependence on component services. For instance, the total price as well as its overall quality depend on all of the component services. Correspondingly, there is a need for rules governing the often diverging motives and interests of the service ecosystem actors.

Regardless of the advantages such as lower search costs (i.e. outcome) that smart integrators promise the customers, contemporary smart integrators often struggle to provide smart service packages (Alt et al. 2019). We assume that this is partly caused by insufficient resource integration by service providers. For instance, such as when there is currently no appropriate service description by service providers that allows a technically automated comparison and bundling of
Fig. 2 AT-based S-D Logic

Perspective on

Value Co-Creation

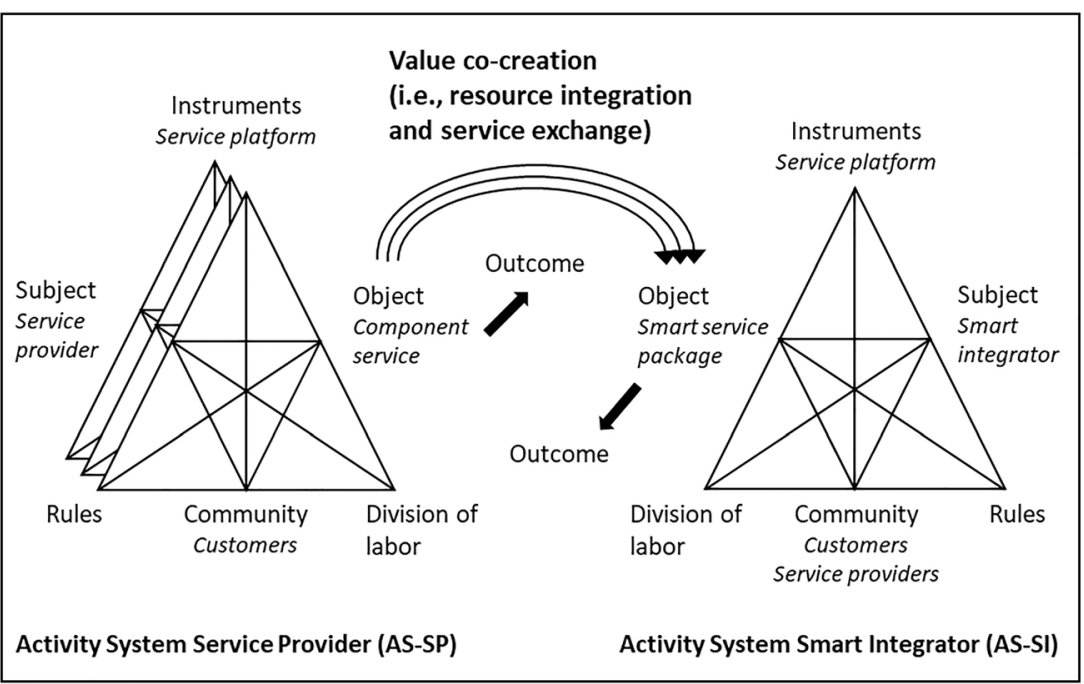


component services (Winter et al. 2012). Drawing on AT, insufficient resource integration actions by service providers indicate contradictions in their higher-level value co-creation activity. In the following, we illustrate exemplary inhibitors (manifestations of contradictions) identified in scientific literature and locate them within the AS-SPs.

According to Schmidt-Rauch and Nussbaumer (2011), two of the most important inhibitors for value co-creation in the case of financial advisory are the so-called dialog problem and the diverging-goals problem. In order to provide a highquality service, an extensive dialogue between the customer and the service provider is necessary. In this dialogue, the customer problem must be revealed through needs assessment and be compared with available solutions. However, when both actors speak different languages, for instance if the service provider uses technical terminology and the customer speaks a natural language, a constructive exchange is difficult and therefore appropriate resource integration actions of a service provider are impeded. Adopting an activity system view, this language example indicates a contradiction within the rules element of an AS-SP.

In contrast, the diverging-goals problem reveals a contradiction between two activity system elements. It refers to the circumstance that the business model and strategies (i.e. instruments) of a service provider are often in conflict with the customer's expectation of symmetric conversation (i.e. rule). For instance, a customer may have the goal of identifying the financial service that best fits her/his needs through an extensive interaction, while the service provider's business model is based on a self-service approach. There are also a number of studies that focus on other sectors (e.g., Minkiewicz et al. 2016; Hildebrandt et al. 2018). For example, based on their analysis of knowledge intensive business services, AarikkaStenroos and Jaakkola (2012) show that there is a risk of inferior service being provided because a collaborative problem solving process (a form of division of labor) is impeded by the belief of service providers (i.e. rules) that customers can not contribute to a successful service provision.

In the case of the service ecosystem of D2D mobility integrators, Albrecht and Ehmke (2016) and Willing et al. (2017a, 2017b) show that not only are there insufficient resource integration actions among service providers, but that most service providers do not conduct service exchange actions. Drawing on our AT-based S-D logic perspective on value co-creation, such a situation is characterized by contradictions located within and between the elements of an AS-SI. A possible inhibitor to service exchange, which is located in the rules element, is described by de Reuver et al. (2009), stating that both service providers and intermediaries, such as a smart integrator, will often be interested in billing the customer.

In summary, drawing on AT, we conceptualize value cocreation by service providers as an activity consisting of two actions - resource integration and service exchange (Vargo and Lusch 2017). Taking the observed limited capabilities of D2D mobility integrators in account to provide smart mobility (Willing et al. 2017a, 2017b; Albrecht and Ehmke 2016), we assume the existence of contradictions in the (potentially) interacting activity systems of mobility providers and a D2D mobility integrator. With an ongoing adaptation process, the service ecosystem actors can try to create a congruence between the elements of the activity systems (Allen et al. 2013), in other words, to eliminate the contradictions in order to put value co-creation into practice.

\section{Research Context and Methodology}

\subsection{Research Context}

In 2017 , more than 10 billion rides were conducted with German public transport companies (Verband Deutscher Verkehrsunternehmen 2018). Public transport in Germany is predominantly organized by transport and tariff associations (TTAs). While TTAs have represented cooperation of independent public transport companies (bus, subway, local train and/or tram) in the past, regional authorities, such as federal states, districts, or cities today increasingly act as (additional) shareholders (Reinhardt 2012). Due to this organizational structure, the decision of a TTA not to engage in value cocreation with a D2D mobility integrator leads to a large local blank spot on the map where none of the mentioned public transport services is available for packaging into smart mobility solutions. Another reason for choosing German TTAs as representatives of mobility providers is that they should be sufficiently familiar with D2D mobility integrators to answer our questions, since the smart mobility concept is most advanced in Europe, in particular in Germany (Willing et al. 2017b).

\subsection{Methodology}

In 2016, there were approximately 124 active TTAs in Germany (Reinhardt 2012; Wikipedia 2016). Using a theoretical sampling method (Flick 2009), we selected 45 TTAs that have not established a value co-creation relationship with a D2D mobility integrator. The selected TTAs vary in terms of the number of public transport companies they represent and the passengers per year. We approached the managing director (MD) of each TTA as primary contact person since $\mathrm{s} / \mathrm{he}$ is responsible for strategic decisions such as cooperation with a D2D mobility integrator. Adopting a snowball sampling method (e.g., Su 2013), we encouraged interviewees to nominate additional or more appropriate experts for interviews. This data collection approach of "using numerous and highly knowledgeable informants" (Eisenhardt and Graebner 2007, p. 28) helps us to mitigate potential bias. We received 
interview confirmations from twelve TTAs. Table 2 presents the interviewees' demographic data and information about their TTA.

We developed a semi-structured interview guideline containing questions about the TTA's activity system and the possible interacted activity system of a D2D mobility integrator. Semi-structured interviews offer high flexibility because they allow open-ended questions and responses to interesting topics that arise spontaneously during the interview (Flick 2009). The questions focused on the different elements of the activity systems, especially on the IT adopted as well as on possible inhibitors. For instance, we asked the interviewees whether the TTA has a mobile ticketing solution or not. If the TTA has no mobile ticketing solution, we tried to find out the inhibitors by asking questions, for example, about the rules established among the members. As recommended by Flick (2009) and Miles et al. (2014), we followed a data triangulation strategy and collected secondary data such as association reports and press releases. We relied on and referred to these secondary data during the interviews to validate the statements of the interviewees. The interviews were conducted in the last quarter of 2016 and lasted between 40 and 75 min each (average $66 \mathrm{~min}$ ).

All interviews were recorded and transcribed. The data was analyzed using the NVivo 10 software program. Data analysis encompassed two cycles and followed an iterative coding approach. In a first cycle, one of the researchers scanned, categorized, and coded the data parallel to data collection. The initial coding scheme built on the interacting activity systems as basic units of analysis in AT (see Fig. 2). Based on the data material, these coding categories were refined. 'Mobile ticketing solution' and 'equipment for the provision of realtime timetable data' are, for example, two of the subcategories of the 'instruments' category. In a second cycle, the codes for each interview were related to each other (Miles et al. 2014), and the sub-categories were, if necessary, redefined and subdivided.

The authors frequently discussed the emerging coding during the entire coding process to address coding bias and to enhance internal validity of the results. The comparison and common interpretation of coded data followed the guidelines proposed by Miles et al. (2014). Data collection was suspended when data saturation was reached, i.e. when incremental learning about the interacted activity systems and the involved inhibitors for value co-creation were minimal (Yin 2014).

\section{Results}

\subsection{Inhibitors for Resource Integration}

We structured our results using our AT-based S-D logic perspective on value co-creation as depicted in Fig. 2. Considering our mobility context, we defined both types of activity systems as AS-MPs in the case of mobility providers and as an AS-MI in the case of a D2D mobility integrator. Based on the AS-MPs, we can analyze the insufficient resource integration actions by TTAs, or more specifically, one of their public transport companies. We focus on the
Table 2 Overview of Interviewees and Represented TTAs

\begin{tabular}{|c|c|c|c|c|c|}
\hline ID & Role / Function & Gender & $\begin{array}{l}\text { Years in } \\
\text { position }\end{array}$ & $\begin{array}{l}\text { Number of public } \\
\text { transport companies }\end{array}$ & $\begin{array}{l}\text { Passengers per year } \\
\text { (in millions) a) }\end{array}$ \\
\hline MD1 & Managing director & Male & 5 & $\geq 40$ & $\leq 400$ \\
\hline MD2 & Managing director & Male & 4 & $\leq 10$ & $\leq 300$ \\
\hline MD3 & Managing director & Female & 6 & $\leq 30$ & $\leq 200$ \\
\hline MD4 & Managing director & Female & 11 & $\leq 20$ & $\leq 50$ \\
\hline MD5 & Managing director & Male & 6 & $\leq 10$ & $\leq 50$ \\
\hline $\begin{array}{l}\text { MD6 } \\
\text { TP1 }\end{array}$ & $\begin{array}{l}\text { Managing director } \\
\text { Transport planning }\end{array}$ & $\begin{array}{l}\text { Male } \\
\text { Male }\end{array}$ & $\begin{array}{l}2 \\
1\end{array}$ & $\leq 30$ & $\leq 50$ \\
\hline MD7 & Deputy managing director & Male & 12 & $\leq 10$ & n.a. \\
\hline $\begin{array}{l}\text { MD8 } \\
\text { PM1 }\end{array}$ & $\begin{array}{l}\text { Deputy managing director } \\
\text { Project manager }\end{array}$ & $\begin{array}{l}\text { Male } \\
\text { Male }\end{array}$ & $\begin{array}{l}6 \\
1\end{array}$ & $\leq 20$ & $\leq 50$ \\
\hline $\begin{array}{l}\text { AR1 } \\
\text { TP2 }\end{array}$ & $\begin{array}{l}\text { Authorized representative } \\
\text { Transport planning }\end{array}$ & $\begin{array}{l}\text { Female } \\
\text { Female }\end{array}$ & $\begin{array}{l}6 \\
2\end{array}$ & $\geq 40$ & $\leq 300$ \\
\hline PM2 & Project manager ${ }^{b)}$ & Male & 2 & $\leq 20$ & $\leq 200$ \\
\hline PM3 & Project manager & Male & 6 & $\leq 30$ & $\geq 700$ \\
\hline OM1 & Office manager & Male & 1 & $\leq 20$ & $\leq 50$ \\
\hline
\end{tabular}

a) Latest available figures

b) The interviewee disclosed that the TTA had recently signed a letter of intent with a D2D mobility integrator. This cooperation has also been made public in the meantime. 
lacking integration of mobile tickets and of real-time timetable information in the mobility service offered to their customers. In addition, a D2D mobility integrator needs a component mobility service in which the two resources are integrated to provide one-stop ticketing and to enable adjustments of the service packages in case of delays or cancellations.

In a first step, we have further specified the elements of the AS-MPs based on the interviews. The overall goal of a public transport company (i.e. subject) is to provide a component mobility service that consists of a transport service and possibly supplementary services (i.e. object) to satisfy customers' mobility needs (i.e. outcome). In the course of the service, the public transport company and its customers use different instruments such as a ticketing machine and a vehicle to obtain the outcome more efficiently. The provision of the component mobility service is also mediated by the customers and the other members of the TTA, such as regional authorities (i.e. community), as well as by the rules and the division of labor. Such rules may include a tariff system, a commission agreement for ticket sales (e.g. MD1, MD5, OM1) and route tenders (e.g. AR1, MD1). The division of labor, among other things, specifies which public transport companies of a TTA are allowed to sell tickets (e.g. MD4, MD5).

Technical progress (e.g., sensors and open data) and the proliferation of mobile devices have the potential to change the provision of the component mobility service accompanied by a change in the instruments element of the AS-MPs. However, as the following results illustrate, German TTAs and their public transport companies often struggle to integrate mobile tickets into their component mobility service.

A first inhibitor for their integration of mobile tickets, and thus for their value co-creation, is located in the upper triangle of the AS-MPs as illustrated in Fig. 3. Public transport is a public good, to which specific explicit and implicit norms are attached. For example, in contrast to private goods, public goods can usually not be offered at cost-covering prices, which makes it necessary to subsidize them with tax money. Many interviewees highlighted that mobile tickets are a "requirement that a customer wants to have at some point" (MD4; see also e.g. MD2, OM1). However, the integration of mobile tickets reflects a supplementary service without "additional revenue” (MD4).

On the other hand, relatively high costs are associated with the introduction of a mobile ticketing solution, resulting in poor cost efficiency. One reason for this is that a mobile ticketing solution "is a permanent cost factor" because it is a "system where I always have to adapt to new mobile device generations" (MD4). In addition, the mobile provider charges a high commission (MD6). As a result, a public transport company "still ends up with less money than it receives from other distribution channels" (MD5). As this quotation shows, the interviewees compared the cost efficiency of different instruments (e.g., ticketing machines and mobile ticketing solution) that can be used for ticket sales. The cost efficiency of mobile ticketing cannot be improved by the termination of another instrument for ticket sale. The reason for this is the explicit norm that public transport should be available to all people, i.e. also to the elderly who do not use a smartphone, for example.

A second inhibitor for the integration of mobile tickets is the division of labor that is historically established in the ASMPs. Currently, due to the explicit organization that is engraved in the earnings allocation contracts, there are few incentives for a public transport company to implement mobile ticketing or to adopt the solution of its TTA. According to the earnings allocation contracts, each public transport company is obliged to report its earnings for each ticket sale instrument, such as mobile ticketing, online store and ticketing machines. Based on this, the TTA calculates the total amount and uses complex "mathematical methods with corresponding projections, [...] to determine the share of the total amount owed to the public transport company $A, B, C$, or D" (MD3, see also MD2, MD5, MD7). This allocation is made based on a variety of information (MD3), for example passenger kilometers or tariff zones. In other words, there is a high division of labor, including a separation between the provision of the transport service and the sale of single ticket types. As a result, a public transport company may refrain from selling mobile tickets. The situation is aggravated if the division of labor is not accompanied by a commission agreement for ticket sales - "we are rural, we are small, in some things we are not up-to-date. At the moment, no commissions are paid in our TTA" (MD4).

Lastly, there is an inhibitor located within the instruments element of the AS-MPs that prevents the integration of mobile tickets in the component mobility service. In the case of AR1 (see also OM1), the existing "IT is not capable of supporting" a mobile ticketing solution because it cannot cover the highly complex tariff system. Most of the major TTAs or the associated large public transport companies possess a mobile ticketing solution that they operate themselves or that is operated by an external mobile ticketing provider (MD1, MD3, MD5, PM3). However, this does not mean that all ticket types are available through mobile devices. For instance, MD2 explained that only single tickets are currently offered.

As already mentioned above, the public transport is a public good. Regional authorities (i.e. community) are pursuing the goal of providing affordable mobility for all people (e.g., elderly, rural dwellers) to meet their need for social and economic participation. In order to achieve this goal, the TTAs are increasingly introducing tenders that represent explicit norms by which they govern the provision of component mobility services by public transport companies. Through these tenders, the TTAs can specify the transport service, for example, by determining how often a particular route is operated. But the supplementary services that are based on the 
Fig. 3 Inhibitors for the Integration of Mobile Tickets and of Real-Time Timetable Information

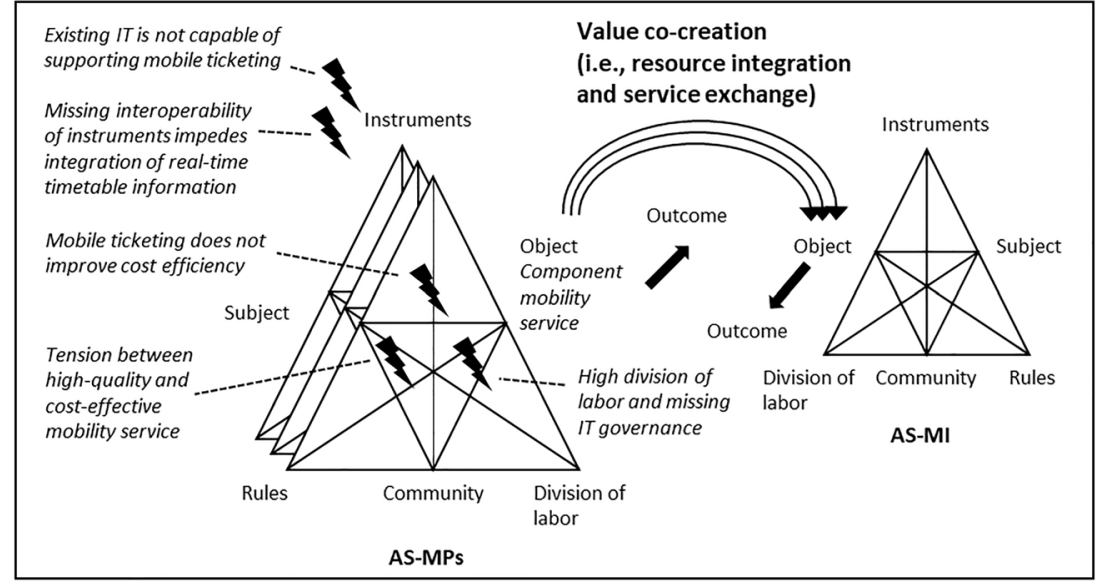

integration of resources, such as real-time timetable information, can also be defined via the tenders.

In this vein, a first inhibitor exists for the integration of realtime timetable information in the relationship between subject and object mediated by the rules if no tenders have been introduced. In such a situation, "cherry picking by public transport companies” (MD4, see also MD7) often develops, which means that desired but economically unattractive route sections are not offered and investments that are necessary for the provision of supplementary services, such as in equipment for the generation of real-time timetable information, are rejected. Explicit norms that result from tenders conducted in the past also have a negative impact on the integration of real-time timetable information. Due to long contract durations, "not all route bundles are tendered in such a way that real-time data provision is prescribed" (PM2).

In addition, there are two different types of tenders that reflect the goals of TTAs to provide a high-quality and/or a cost-effective component mobility service to different degrees. Gross tendering (e.g. MD3, MD7) means that a public transport company receives a fixed price for the provision of the component mobility service, while the passenger income remains with the carrier (i.e. TTA and its regional authorities). As a result, a public transport company has an interest in minimizing its costs, i.e. it will only integrate real-time timetable information if specified in the tender. In net tendering (e.g. MD1) in comparison, a public transport company obtains passenger income as well as possibly additional grants - "in the case of public train transport, I know of no situation nationwide where public transport companies operate without extra grants" (MD7). In this case, the public transport company will evaluate whether the integration of real-time timetable information can attract new customers and if the additional revenues will compensate for the costs incurred.

A second inhibitor for the integration of real-time timetable information exists within the instruments element of the ASMPs. For integration of real-time timetable information, vehicles such as busses must be equipped with sensors and the IT in the control centre must be adapted. In practice, for instance, "especially small bus companies struggle with technical implementation. That sounds so simple real-time, but when one must do it, it is really considerably more complex and complicated" (PM2). Overall, most interviewees (e.g. AR1, MD3, MD4, OM1, TP1) explained that some of their public transport companies are unable to integrate real-time timetable information into their component mobility service due to the presence of one or more of the identified inhibitors.

\subsection{Inhibitors for Service Exchange}

Our analysis also focused on the inhibitors for the service exchange action of TTAs and their public transport companies, the second action of their value co-creation activity. If a public transport company conducts a service exchange with a D2D mobility integrator, it becomes a part of its service ecosystem and thus of its activity system (i.e. community), which is denoted as AS-MI.

AS-MI focuses on the provision of a smart mobility service (i.e. object) to better satisfy customers' mobility needs (i.e. outcome). The transformation of several component mobility services (each object of an AS-MP) into a smart mobility service through a D2D mobility integrator (i.e. subject) is mediated by a number of instruments, such as a smartphone app (i.e. a service platform), algorithms, and sensors, which enable a more efficient transformation of the object. Furthermore, the actors of the community, for example, an individual customer, TTAs, and multiple mobility providers such as bike- and car-sharing companies, and their goals influence the transformation. The further mediating elements are the established rules, such as guidelines for packaging the component mobility services and standards for information exchange, as well as the division of labor. For instance, a customer must continuously provide real-time information about her/his current geographical position via the smartphone app. 
The interviews with the German TTAs revealed a number of inhibitors for their service exchange action: A first inhibitor (inhibitors are marked bold in the following) concerns the object of the AS-MI (see Fig. 1) and is based on two goals of the TTAs that differ from the goal of the D2D mobility integrator - (1) to provide smart local mobility in the future themselves, and (2) not to make efforts in the short term to support the provision of supra-regional smart mobility. A majority of German TTAs and their public transport companies currently "depend very heavily on pupils" (MD4, see also AR1, MD5, MD8, OM1), since the state subsidies they receive for free or discounted transport of pupils between home and school represent a large part of their revenues. However, demographic changes in Germany will have a negative impact on the future number of pupils. Hence, to reduce this dependency, TTAs are trying to attract additional customer groups such as commuters.

In recent years, most TTAs have initiated marketing partnerships (e.g. offering price discounts) with local mobility providers such as taxi, bike- or car-sharing companies to make their component mobility services more attractive in comparison to private car use: "We pass on the information, that's true. So that we simply say: Here, these are the taxi companies, here is the contact information, [and] you can call them. We have been doing this for a very long time" (MD4), and "at some point, [name of the car-sharing company] approached us and asked if they could offer our subscription customers a benefit. [...]. So, it was initially only a pure marketing cooperation without any money that would have flowed" (MD5, see also PM2).

Given the new technical possibilities, TTAs themselves plan to offer smart mobility in the future by packaging their own component mobility service and those of their cooperation partners. However, the projects to establish a service platform (usually in form of a smartphone app) are so far mostly in beginning stages (MD3, MD5, MD7, MD8, PM1, PM2, PM3). TTAs in particular struggle to include the component mobility services of the cooperation partners because they have been "until now also technically a few meters behind in this regard", and "they are to some degree analogue, in terms of the technical equipment of the vehicles, and in terms of their rental system" (PM2, see also MD1, MD5).

In addition, the TTAs are not willing to conduct a service exchange with a D2D mobility integrator, since their goal - at least in the short term - is not the realization of supra-regional smart mobility. This is because the TTAs have their own histories due to their projects that encompass negative experiences with regard to the object 'smart mobility service': "this is a very delicate flower, but it is growing. However, in view of the total volume, it is a niche [i.e. "a stable customer base of 1,000 persons"]" (MD2) and "the number of users has not grown enormously due to this cooperation" (MD5). As a result, the TTAs questioned the object of the activity of a
D2D mobility integrator: "therefore we are also a little cautious with initiatives that somehow require all [service] platforms of the world to be connected in order to offer the customers a very high benefit. [...]. And that is why our philosophy is initially to make our core business decent-first of all, to make sure that the smart mobility service that we offer here [...] that there is a market [for it] at all"' (MD2; see also MD7, MD8). The current small customer group that conducts trips through two or more TTA areas - "collapsing and breaking out transport are the remaining 3\%. This is somewhat clear" (MD7, see also e.g. MD2, MD3) - also contributes to questioning the object. This inhibitor for the service exchange by TTAs is shown in Fig. 4.

A second inhibitor for the service exchange by TTAs is located in the triangle of subject, object, and community of the AS-MI. The interviewees expected that a D2D mobility integrator is not able to transform the different component mobility services into a smart mobility service that is attractive for customers (not an offering that "will be really successful in the market" - MD4), since only a few mobility providers belong to the community. This expectation is based on the fact that the majority of the interviewees have not yet been contacted by D2D mobility integrators: "I think we are actually a bit too small [...]. They are not the ones who are coming to us and saying: We want to do something with you!" (MD4 see also e.g. MD3, MD8). In the case of MD5, this expectation is further supported by the observation of a stagnating development of participation by mobility providers "for example, in the case of Qixxit, one has the feeling it will not go any further" (MD4, see also MD5).

An expected loss of corporate identity if component mobility services were packaged into a smart mobility service is a further inhibitor for the service exchange by TTAs. A D2D mobility integrator uses its own service platform (usually a smartphone app) as an instrument to facilitate the transformation. However, the TTAs have a more traditional understanding of the division of labor and see themselves as the direct customer contact. This tension is reflected in their desire that a white label solution, i.e. a smartphone app that is not provided under the brand name of the D2D mobility integrator (e.g. MD1, PM2, TP1), is offered: "a customer should really see - with the name, with the logo - that s/he is getting there using the public transport in our area. We would like to integrate component mobility services under this framework [i.e. a white label solution]. We did not want to re-invent it, but we're going to give them that and the customer then gets access through us, but actually uses Moovel. But then s/he is not irritated or thinking: What is Moovel? I want to take [the name of the TTA]" (TP1). This is a "compromise that one has included this regional element and that it will not become completely anonymous" (PM1).

A final inhibitor for the service exchange is an expected overreach by a D2D mobility integrator. Based on their 
Fig. 4 Inhibitors to Service Exchange

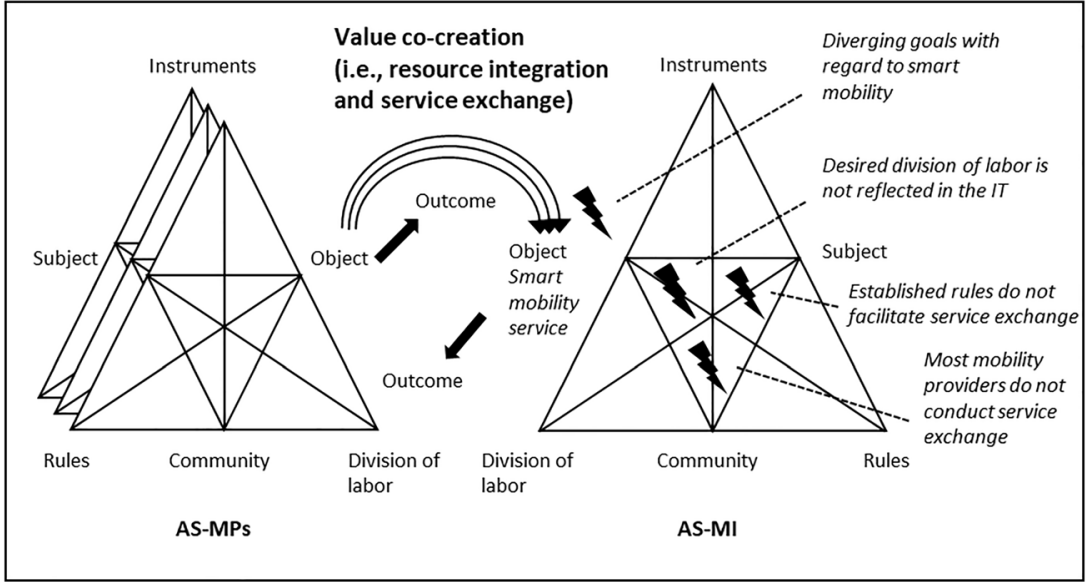

experiences, some TTAs have developed an implicit norm (i.e. rules) that limits their participation in the activity of specific D2D mobility integrators. For example, MD7 had already had negative experiences with the provision of realtime timetable information for the relatively simple timetable information of Deutsche Bahn AG (which is the parent company of the provider of the Qixxit app) in the past: "The blame is always put on technical problems or mistakes in the delivery by public transport companies and there are mutual recriminations". However, "it can be quite advantageous if I, as Deutsche Bahn AG, prioritize information in my information system about my public transport companies and work with real-time timetable information and integrate information from my competitors, such as private train companies afterwards. But that is a presumption or an accusation". In addition, interviewees feared disclosing information that could subsequently be used against them in the case of a tender. For instance, AR1 (see also MD2) stated that "it is always difficult if a top dog offers something like that. You are always sceptical [...] simply because they somehow have some knowledge that they could theoretically use in the next tender". As a result, "it probably has to be a neutral [service] platform" (MD3). In other words, the provider of the service platform should be a public body or a company outside of the mobility sector.

\subsection{Adaptations to Facilitate Value Co-Creation}

According to Allen et al. (2013), the contradictions inherent in an activity system can be transformed into congruencies through a process of feedback and action. This idea fits well with the S-D logic perspective, which assumes that by "breaking, making, and maintaining" the institutional arrangements, value co-creation can be increased in a service ecosystem (Koskela-Huotari et al. 2016, p. 2964). In the following, we explain the adaptations made by the TTA of PM2 and a D2D mobility integrator to achieve congruence between the elements of the previously non-interacting activity systems
(AS-MP and AS-MI). Shortly before the interview was conducted, the TTA signed a letter of intent with the D2D mobility integrator to sign a contract by the end of the following month. This cooperation has also been made public in the meantime. Given the relatively high consistency of inhibitors that TTAs experience, the case of PM2 can serve as a blueprint.

In our previous results, we showed various inhibitors faced by TTAs that prevent their resource integration and service exchange actions, in other words, the establishment of a value co-creation relationship with a D2D mobility integrator. In the case of PM2, in line with our AT-based S-D logic perspective on value co-creation, its TTA and a D2D mobility integrator have made a number of adaptations in their activity systems to transform the inhibitors into congruencies, and thus to facilitate value co-creation. The trigger for the adaptations was that the TTA questioned the object of its current activity (AS-MP). Due to technological progress and actual customer needs, the TTA considered it no longer appropriate to offer its customers transport between stations. The TTA instead has the goal of providing smart mobility for its local geographical area. In this respect, the TTA differs from the other TTAs that are not currently pursuing this goal or that had already initiated a project to establish a corresponding service platform in the past (e.g. MD2, MD4).

At present, however, due to the mobile ticketing solution (i.e. instrument) adopted, the TTA is not able to efficiently transform the object, and thus to achieve its goal (AS-MP). The interviewee pointed out that the mobile ticketing solution is not suitable for such a purpose, because the provider is not innovative enough - "pace of innovation leaves a lot to be desired" (PM2). In addition, the project for the development of an own service platform has just been started, and the "solution will be available at the earliest in two and a half to three years, and what will we do until then?" (PM2).

The identified inhibitor, which is located in the upper triangle of the AS-MP, is transformed into a congruence through the feedback provided by the D2D mobility integrator and the 
corresponding adaptations. A first adaptation was that "we let our own mobile ticketing expire. [...]. We do not have to worry about our own mobile ticketing" (PM2). From the viewpoint of the complementary S-D logic perspective, this represents a breaking of existing institutional arrangements. By discontinuing the mobile ticketing solution, the provider also leaves the community of the activity. As a result, no mobile tickets can be integrated into the component mobility service (i.e. object) by the TTA. Table 3 shows the adaptations made by the TTA and the D2D mobility integrator to facilitate value co-creation by the TTA.

Adaptations to create congruencies are not, however, limited to the activity system of the TTA (AS-MP). The D2D mobility integrator has also made adaptations to its activity system (AS-MI), so that the TTA is willing to conduct service exchange, and that both activity systems thus become interacted. The goal of the activity of the D2D mobility integrator is still the provision of smart mobility for customers. However, in order to overcome the existing inhibitors for value co-creation (see Fig. 4), a white label smartphone app has been introduced as an instrument: we will "receive, so to speak, a [name of the TTA] colored [name of the smartphone app]" and "it is also the first time that they have offered something like that" (PM2). The smartphone app includes a ticketing function that enables the integration of mobile tickets into the smart mobility service.

The provision of the white label smartphone app is linked to further adaptations in elements of the AS-MI. The white label smartphone app reflects the desire of the TTAs to maintain direct customer contact (i.e. division of labor), at least from the viewpoint of the customers. There were also adaptations in the case of the community element. Prior to the introduction of the white label smartphone app, the focus was on providing smart mobility for a not further specified group of customers. Because the TTA now acts as a provider in the external presentation to customers, the focus is on the (potential) public transport customers in its local geographical area (i.e. community). The regional focus also ensures that the D2D mobility integrator can provide smart mobility in an efficient way since fewer mobility providers need to be taken into account. In addition, the TTA and its public transport companies already provide a wide range of necessary component mobility services.

\section{Discussion}

\subsection{Theoretical Implications}

This article makes five major theoretical contributions to big data and business analytics (Pappas et al. 2018; Mikalef et al. 2020), smart integrator (Alt et al. 2019) and S-D logic literature (Vargo and Lusch 2017; Brust et al. 2017). First, we contribute to the understanding of actors in big data and business analytics ecosystems, as called for by Pappas et al. (2018). In the past, big data and business analytics approaches have been implemented in particular to solve technical and business challenges. Less research has considered how actors in big data and business analytics ecosystems exchange data, information and knowledge in order to drive digital transformation and create sustainable societies, for instance, with regard to environmental sustainability (e.g., mitigation of noise and air pollution that is caused by private cars) (Pappas et al. 2018; Gupta et al. 2018). Our study provides insights into the
Table 3 Adaptations to Facilitate Value Co-Creation

\begin{tabular}{|c|c|c|}
\hline $\begin{array}{l}\text { Form of } \\
\text { adaptation }\end{array}$ & $\begin{array}{l}\text { Affected element (part of the } \\
\text { interacting activity systems) }\end{array}$ & Explanation \\
\hline Addition & Community (AS-MI) & $\begin{array}{l}\text { By conducting resource integration and service exchange, } \\
\text { the TTA and its public transport companies become } \\
\text { members of the community. }\end{array}$ \\
\hline \multirow[t]{5}{*}{ Modification } & Community (AS-MI) & $\begin{array}{l}\text { A new focus on the (potential) customers of the TTA and its } \\
\text { public transport companies. }\end{array}$ \\
\hline & Division of labor (AS-MI) & $\begin{array}{l}\text { Due to the white label smartphone app, the TTA is able to } \\
\text { maintain direct customer contact. }\end{array}$ \\
\hline & Instrument (AS-MI) & Introduction of a white label smartphone app. \\
\hline & Object (AS-MI) & $\begin{array}{l}\text { The new goal is to provide smart local mobility on behalf of } \\
\text { the TTA. Now provision of a smart local mobility service, } \\
\text { including the integration of mobile tickets. }\end{array}$ \\
\hline & Object (AS-MP) & $\begin{array}{l}\text { The new goal is to provide smart local mobility. Now } \\
\text { provision of a component mobility service without the } \\
\text { integration of mobile tickets. }\end{array}$ \\
\hline \multirow[t]{2}{*}{ Substitution } & Community (AS-MP) & $\begin{array}{l}\text { The business relationship with the mobile ticketing provider } \\
\text { is terminated. }\end{array}$ \\
\hline & Instrument (AS-MP) & Termination of the mobile ticketing solution. \\
\hline
\end{tabular}


attributes and beliefs of German TTAs, which enhance our knowledge of their behavior, capabilities and needs, as well as on the data they generate and how they interact. In addition, by focusing on the lacking data exchange between TTAs (public) and a D2D mobility integrator (private), our research complements studies that analyze public, respectively, private actor relationships (e.g., Klievink et al. 2017; Popovič et al. 2018; Côrte-Real et al. 2020).

Second, we contribute to research on smart integrators, especially in a mobility context, which is in the fledgling stage and has only received limited attention by scholars to date. Existing work provides a market overview on the current development stage of the smartphone apps of D2D mobility integrators, but does not explain the provision of non-smart mobility services (Albrecht and Ehmke 2016; Willing et al. 2017a, 2017b). Other studies showed that mobility providers often do not have the necessary resources, such as mobile tickets and real-time timetable information (Schulz et al. 2018), or do not make them available, for example due to a lack of pressure for legitimation (Schulz and Überle 2018). What has been missing to date is a study on how to initiate a business relationship between a mobility provider and a D2D mobility integrator.

Our third contribution is the integration of AT and the $S-D$ logic perspective. AT has been successfully applied in a number of research fields (Kuutti 1996; Kaptelinin 1996; Jarzabkowski 2003; Blackler et al. 2000; Engeström 2000a, etc.), including IS (e.g., Hasan et al. 2017; Allen et al. 2013; Karanasios and Allen 2013, 2014; Sun 2020; Slavova and Karanasios 2018; Malaurent and Karanasios 2020). The focus was already on work activities of individuals, teams, and companies (Karlsson and Wistrand 2006; Korpela et al. 2004; Zott and Amit 2009; Engeström 2000b). In contrast, the S-D logic perspective and its concept of value co-creation are metatheoretical in nature today, making their "direct testing, verification, and application" difficult (Vargo and Lusch 2017, p. 50). By complementing the S-D logic perspective with AT, we follow the recent call to use theories outside of marketing to develop the S-D logic perspective towards midrange theory (Vargo and Lusch 2017; Schulz et al. 2020). In doing so, we rely on the argumentation of Vargo and Lusch (2017) that resource integration and service exchange are the two building blocks of value co-creation. This is in line with the assumption that actor engagement (which is defined as the disposition of an actor to engage and its activity of integrating resources) can be used as a microfoundation for value co-creation (Storbacka et al. 2016).

Based on literature from different service fields such as education, finance, and mobility (Nueesch et al. 2014; Zhang et al. 2006, etc.), we show that resource integration and service exchange of service providers (i.e. their value co-creation) can be analyzed using an interacting activity systems perspective. With this AT-based S-D logic perspective on value co-creation, we provide a blueprint for the analysis of (lacking) value co-creation between actors embedded in different service ecosystems. Since the instruments element of an activity system can map the concept of the service platform from the S-D logic perspective, the blueprint can help researchers to shed light on value co-creation of actors in a technology-enabled service context that we currently know little about (Breidbach and Maglio 2016).

Fourth, we show that the AT-related concept of contradictions (Engeström 1987) can be used to identify inhibitors that represent manifestations of contradictions, which affect value co-creation by service providers. Initially, based on exemplary inhibitors for value co-creation described in scientific literature (e.g., Schmidt-Rauch and Nussbaumer 2011; Aarikka-Stenroos and Jaakkola 2012), we illustrate that these inhibitors are located within elements, between them, or between elements of different activity systems. Subsequently, we have checked this theoretical derivation with our qualitative study. The interviews confirmed that the concept of contradictions can be applied to identify inhibitors for value co-creation faced by German TTAs and thus hinder the provision of smart mobility. With this theoretical contribution, we extend the work of Schulz et al. (2020), who adopted AT thinking for analyzing value co-creation, but without drawing on interacting activity systems as the unit of analysis (Engeström 2001), and not referring to the different levels of contradictions (Engeström 1987).

Our final theoretical contribution is to show how inhibitors are transformed into congruencies (Allen et al. 2013) through a process of feedback and action that facilitate the value cocreation by a TTA. According to the S-D logic perspective, "breaking, making, and maintaining the institutionalized rules of resource integration" (Koskela-Huotari et al. 2016, p. 2964) leads to new opportunities for value co-creation in a service ecosystem. By drawing on AT, we can provide a broader theoretical foundation by showing that the actors transform inhibitors for value co-creation through adding, substituting, or modifying activity system(s) elements into congruencies. In the case of PM2, its TTA and a D2D mobility integrator have initiated a number of adaptations. In particular, the desire of the TTA to offer smart local mobility in the short term and the simultaneous inability of the D2D mobility integrator to provide smart mobility for customers can be seen as the starting point for adaptations. Although we could only observe how inhibitors are transformed into congruencies in this case, the statement of MD1 - "we had [...] a system decision here. Either we extend the electronic timetable information that we have been using for more than 20 years or we switch to an external mobility [service] platform" - also supports our AT-based thinking that inhibitors can serve as triggers for adaptations that facilitate value co-creation. 


\subsection{Practical Implications}

Our study provides a number of practical contributions. Initially, we improve practitioners' knowledge on IT-enabled value co-creation in service ecosystems in general by introducing our AT-based S-D logic perspective. In different service sectors, such as education, finance, health, and mobility, a single service provider is often not able to meet the actual customer needs (Alt et al. 2019). Technological progress has the potential to foster value co-creation between different service providers by developing "technologies [for example service platforms] that rely on sensors, big data, open data, new ways of connectivity and exchange of information (e.g., Internet of Things, RFID, and NFC) as well as abilities to infer and reason" (Gretzel et al. 2015, p. 179). However, little advice is offered in S-D logic literature to date on how value cocreation can be put into practice (Giesbrecht et al. 2017; Vargo and Lusch 2017).

By adopting AT as complementary theoretical lens, we highlight the elements - the six elements of each activity system - that practitioners need to take into consideration. In addition, we create an awareness that these elements are linked and cannot be viewed separately from each other (Engeström 1987, 2001). This awareness is particularly important when a new IT is adopted by the actors of a service ecosystem in the course of technological progress in order to identify possible inhibitors for value co-creation in advance and to initiate necessary adaptations.

In addition, the AT-based S-D logic perspective reflects a theory-based blueprint that can be used by practitioners of all service fields to systematically analyze the two underlying actions of the value co-creation activity - resource integration and service exchange. On the basis of the interviews with the German TTAs, we exemplarily show how the general elements of the interacting activity systems need to be specified during the analysis. Building on this, we identified the inhibitors to resource integration on the part of the TTAs and their public transport companies. In the case of the lacking integration of mobile tickets and of real-time timetable information, our results show, for example, that the existing IT is not capable of supporting mobile ticketing and that there is a tension between the provision of a high-quality and costeffective component mobility service caused by differing rules. Practitioners can use the results to initiate actions for the mitigation and resolution of the inhibitors to resource integration.

The AT-based S-D logic perspective on value co-creation also gives practitioners insights into possible solutions to the problems of inhibitors for resource integration faced by service providers. In the case of the lacking resource integration by German TTAs, the regional authorities as their frequent shareholders (Reinhardt 2012), and thus members of the community element of the activity system, play a central role in our considerations. Due to their position, they should have, for example, the power to initiate and enforce a change of rules. For instance, they can ensure that the implementation of a mobile ticketing solution becomes more economically attractive for public transport companies by advocating that earnings allocation contracts are adapted appropriately and a commission agreement for ticket sales is introduced. In addition, with regard to the integration of real-time timetable information, the regional authorities can use their influence to enforce the use of gross tendering. If public transport companies receive a (higher) fixed price for the provision of their component mobility service, they can be obliged to integrate realtime timetable information.

The AT-based S-D logic perspective on value co-creation can also be used by practitioners to identify inhibitors to service exchange that are faced by service providers. Our results show that TTAs and their public transport companies do not currently conduct service exchange with a D2D mobility integrator because they wish, for instance, to maintain direct customer contact (i.e. to retain the traditional division of labor). However, this wish is not reflected in the smartphone app integrated by D2D mobility integrators.

A further practical contribution is that on the basis of the AT-based S-D logic perspective, solutions can be proposed to overcome the inhibitors for service exchange. A theory-based recommendation could be that the regional authorities should prevent negative service exchange decisions of TTAs that are guided by their goal to provide smart local mobility in the future themselves and the perceived lack of necessity to make efforts in the short term to support the provision of supraregional smart mobility. Such attempts to defend 'local empires', and the associated lack of focus on actual customer needs contribute to the attractiveness of private car use. As a result, cities continue to face such problems as traffic congestion, parking problems as well as noise and air pollution (Willing et al. 2017a, 2017b; Gupta et al. 2019; Benevolo et al. 2016; Schreieck et al. 2018).

While theory-based recommendations for facilitating resource integration and service exchange of service providers are possible based on the AT-based S-D logic perspective, we can also provide a real-world case (PM2) for mobility providers that can serve as blueprint for other practitioners. Our results show how the TTA and the D2D mobility integrator each adapted their activity system. The mobility provider, for example, no longer integrates mobile tickets, however, makes its component mobility service available to the D2D mobility integrator. The D2D mobility integrator, in turn, now provides a white label smartphone app and integrates mobile tickets into smart local mobility service. We assume that the D2D mobility integrator is able to facilitate value co-creation by other TTAs through the integration of other resources. For instance, Willing et al. (2017a, p. 277) emphasized that "generated data on [service platforms] creates the unique 
opportunity for service providers [i.e., mobility providers] to analyze how their individual business model performs in the context of competing and complementary services". Based on the results of big data analytics, TTAs can for example leave the final pricing to the D2D mobility integrator (Schulz et al. 2018).

The recommendations made so far aim at increasing the quality of data generated by TTAs and improving data access for D2D mobility integrators, but there is also a need to improve the big data analytics capability of both actors. According to Pappas et al. (2018), this includes the developing a data-driven culture, investing in appropriate technology, facilitating technical and managerial skills, and promoting a climate of organizational learning. This capability enables the actors to generate value from big data and to achieve business and societal change. Hence, a strong big data analytics capability is key for digital transformation and the creation of sustainable societies.

To develop big data analytics capability, D2D mobility integrators should, for example, hire a workforce with extensive technical and managerial skills in big data analytics. Since D2D mobility integrators are often start-ups (Albrecht and Ehmke 2016) competing with well-established companies for the most qualified talent, D2D mobility integrators should offer attractive salaries, benefits, working conditions and training opportunities. In the long term, strategic educational reform in big data analytics is needed to develop qualified talent (Watson 2019), possibly modelled after new curricula proposed by Gupta et al. (2015) and Wilder and Ozgur (2015).

For TTAs currently focused on providing public transportation, a new data-driven culture among employees is needed to participate actively in big data and business analytics ecosystems. This need is bolstered by studies (e.g., Klievink et al. 2017; Okwechime et al. 2018) finding big data analytics capability to be less present in public organizations than in private companies and by studies (e.g., Davenport and Bean 2018) showing that established companies can find it more difficult to shift to a data-driven culture than start-ups adopting a data-driven culture from their beginning. One way to promote a data-driven culture is to assign management roles focussing on big data and business analytics (Davenport and Bean 2018). A stronger data-driven culture among TTAs increases the quantity and quality of data that, in turn, facilitate value creation among actors (Côrte-Real et al. 2020), leading to business and societal change and the creation of sustainable societies (Pappas et al. 2018).

\subsection{Limitations and Future Research}

In our study, we adopted the S-D logic perspective to analyze the (lack of) value co-creation of German TTAs and their public transport companies. Originally introduced into marketing (Vargo and Lusch 2004), the S-D logic perspective has since been used by scholars from many different research fields, including IS (see Brust et al. 2017 for an overview). In addition, some of the previous studies have focused on mobility (e.g., Hein et al. 2018; Schulz and Überle 2018; Alexander and Jaakkola 2011; Echeverri and Skålén 2011; Schulz et al. 2020). However, there are numerous other perspectives and theories that also deal with the concept of value co-creation (Kohtamäki and Rajala 2016; Reypens et al. 2016). While we make an important theoretical contribution to develop the S-D logic perspective towards a midrange theory and framework, as requested by Vargo and Lusch (2017), it is unclear how the explanatory power of the S-D logic perspective is in comparison to the other perspectives and theories.

A similar argument concerns the choice of AT as complementary theory. As recommended, AT does not originate from marketing (Vargo and Lusch 2017) and has already been used to analyze work activities at the team and (cross-) company level (Karlsson and Wistrand 2006; Korpela et al. 2004; Engeström 2000b; Schulz et al. 2020). Nevertheless, the choice of a different complementary theory may cause varying results. Future research should address the question concerning in which cases the use of the AT-based S-D logic perspective leads to superior results.

The empirical data used in this study was only collected from the German mobility sector and the results may therefore not be directly transferable to other countries and fields of service. Although the mobility sector is regarded to be an important area for smart integrators (Alt et al. 2019), and the concept of smart mobility is considered to be very advanced in Europe and especially in Germany (Willing et al. 2017b), further research needs to prove the generalizability of our results. An interesting setting may be found in the medical tourism sector, in which (smart) integrators package different component services like medical treatment, translation, accommodation and transfer (Connell 2006).

Our approach of conducting qualitative interviews with experts is recommended and acknowledged in research fields that undergo a great deal of change (Flick 2009). As a next step however, further qualitative as well as quantitative analyses are needed to ensure the validity of our results. The timeframe of our data collection was also limited. We were only able to take snapshots of the initiated adaptations to create congruencies. Future research should employ longitudinal studies to track the process of feedback and action over a longer period of time.

Lastly, even though component mobility services of TTAs and their public transport companies are considered an important part of smart mobility (Willing et al. 2017b), future research should examine the activity systems of further mobility providers such as taxi and bike-sharing companies. In addition, the value co-creation relationship between a D2D mobility integrator and a customer requires more detailed 
investigation. Because our AT-based S-D logic perspective on value co-creation can also be used from a customer perspective instead of, or in addition to, a mobility provider perspective, it can serve as a theoretical foundation.

\section{Conclusion}

D2D mobility integrators currently fail to provide truly smart mobility. However, our understanding regarding the lack of value co-creation by the mobility providers as the root cause, as well as our knowledge of possible solutions is limited. We contribute to closing these research gaps by adopting an ATbased S-D logic perspective to analyze the lack of value cocreation by German TTAs and their public transport companies. Based on this, we can identify different inhibitors for their resource integration and service exchange actions that constitute their value co-creation activity. Our results also show how a TTA and a D2D mobility integrator have started a series of adaptations to put value co-creation into practice.

Funding Information Open Access funding provided by Projekt DEAL. This work was supported by the Bavarian State Ministry of Science and the Arts.

Thomas Schulz was supported by the BayWISS Consortium, Digitization.

The responsibility remains with the authors.

\section{Compliance with Ethical Standards}

Conflict of Interest The authors declare that they have no conflict of interest.

Open Access This article is licensed under a Creative Commons Attribution 4.0 International License, which permits use, sharing, adaptation, distribution and reproduction in any medium or format, as long as you give appropriate credit to the original author(s) and the source, provide a link to the Creative Commons licence, and indicate if changes were made. The images or other third party material in this article are included in the article's Creative Commons licence, unless indicated otherwise in a credit line to the material. If material is not included in the article's Creative Commons licence and your intended use is not permitted by statutory regulation or exceeds the permitted use, you will need to obtain permission directly from the copyright holder. To view a copy of this licence, visit http://creativecommons.org/licenses/by/4.0/.

\section{References}

Aarikka-Stenroos, L., \& Jaakkola, E. (2012). Value co-creation in knowledge intensive business services: A dyadic perspective on the joint problem solving process. Industrial Marketing Management, 41(1), $15-26$.

Ahlers, D., Akerkar, R., Krogstie, J., Opdahl, A. L., Tessem, B., \& Zhang, W. (2018). Harnessing mobility data in cities: A case study from the Bergen region. Svalbard: Norsk konferanse for organisasjoners bruk av informasjonsteknologi.
Akande, A., Cabral, P., \& Casteleyn, S. (2019). Assessing the gap between technology and the environmental sustainability of European cities. Information Systems Frontiers, 21, 581-604.

Albrecht, L., \& Ehmke, J. F. (2016). Innovative Services in der Mobilitätsbranche: Eine Marktanalyse multimodaler Mobilitätsmanager. Ilmenau: Multikonferenz Wirtschaftsinformatik.

Alexander, M., \& Jaakkola, E. (2011). Exploring value co-creation within networks: Actor-to-actor service provision within a public transport service system. Glasgow: Industrial Marketing and Purchasing Conference.

Allen, D. K., Brown, A., Karanasios, S., \& Norman, A. (2013). How should technology-mediated organizational change be explained? A comparison of the contributions of critical realism and activity theory. MIS Quarterly, 37(3), 835-854.

Alt, R., Ehmke, J. F., Haux, R., Henke, T., Mattfeld, D. C., Oberweis, A., Paech, B., \& Winter, A. (2019). Towards customer-induced service orchestration - requirements for the next step of customer orientation. Electronic Markets, 29(1), 79-91.

Beirão, G., \& Cabral, J. A. S. (2007). Understanding attitudes towards public transport and private car: A qualitative study. Transport Policy, 14, 478-489.

Benevolo, C., Dameri, R. P., \& D'Auria, B. (2016). Smart mobility in smart city: Action taxonomy, ICT intensity and public benefits. In T. Torre, A. M. Braccini, \& R. Spinelli (Eds.), Empowering organizations: Enabling platforms and Artefacts (pp. 13-28). Cham: Springer.

Blackler, F., Crump, N., \& McDonald, S. (2000). Organizing processes in complex activity networks. Organization, 7(2), 277-300.

Breidbach, C. F., \& Maglio, P. P. (2016). Technology-enabled value cocreation: An empirical analysis of actors, resources, and practices. Industrial Marketing Management, 56, 73-85.

Brust, L., Breidbach, C. F., Antons, D., \& Salge, T. O. (2017). Servicedominant logic and information systems research: A review and analysis using topic modeling. Seoul: International Conference on Information Systems.

Connell, J. (2006). Medical tourism: Sea, sun, sand and ... surgery. Tourism Management, 27(6), 1093-1100.

Côrte-Real, N., Ruivo, P., \& Oliveira, T. (2020). Leveraging internet of things and big data analytics initiatives in European and American firms: Is data quality a way to extract business value? Information \& Management, 57(1), 103141.

Dai, H., Ge, L., \& Liu, Y. (2018). Information matters: An empirical study of the efficiency of on-demand services. Information Systems Frontiers.

Davenport, T. H., \& Bean, R. (2018). Big companies are embracing analytics, but most still don't have a data-driven culture. Harvard Business Review.

Davydov, V. V., Zinchenko, V. P., \& Talyzina, N. F. (1983). The problem of activity in the works of a. N. Leont'ev. Soviet Psychology, 21(4), 31-42.

de Reuver, M., Bouwman, H., \& Haaker, T. (2009). Mobile business models: Organizational and financial design issues that matter. Electronic Markets, 19(1), 3-13.

Dennehy, D., \& Conboy, K. (2020). Breaking the flow: A study of contradictions in information systems development (ISD). Information Technology \& People, 33(2), 477-501.

Dionne, P., \& Bourdon, S. (2018). Contradictions as the driving force of collective and subjective development group employment programmes. Journal of Education and Work, 31(3), 277-290.

Echeverri, P., \& Skålén, P. (2011). Co-creation and co-destruction: A practice-theory based study of interactive value formation. Marketing Theory, 11(3), 351-373.

Eisenhardt, K. M., \& Graebner, M. E. (2007). Theory building from cases: Opportunities and challenges. Academy of Management Journal, 50(1), 25-32. 
Elliot, S. (2011). Transdisciplinary perspectives on environmental sustainability: A resource base and framework for IT-enabled business transformation. MIS Quarterly, 35(1), 197-236.

Engeström, Y. (1987). Learning by expanding: An activity-theoretical approach to developmental research. Orienta-Konsultit: Helsinki.

Engeström, Y. (1993). Developmental studies of work as a testbench of activity theory: The case of primary care medical practice. In S. Chaiklin \& J. Lave (Eds.), Understanding practice: Perspectives on activity and context (pp. 64-103). Cambridge: Cambridge University Press.

Engeström, Y. (2000a). Activity theory and the social construction of knowledge: A story of four umpires. Organization, 7(2), 301-310.

Engeström, Y. (2000b). Activity theory as a framework for analyzing and redesigning work. Ergonomics, 43(7), 960-974.

Engeström, Y. (2001). Expansive learning at work: Toward an activity theoretical reconceptualization. Journal of Education and Work, 14(1), 133-156.

Engeström, Y., \& Sannino, A. (2011). Discursive manifestations of contradictions in organizational change efforts. A methodological framework. Journal of Organizational Change Management, 24(3), 368-387.

Flick, U. (2009). An introduction to qualitative research. London: SAGE Publications.

Follmer, R., \& Gruschwitz, D. (2019). Mobilität in Deutschland - MiD Kurzreport.

Gebauer, H., Johnson, M., \& Enquist, B. (2010). Value co-creation as a determinant of success in public transport services: A study of the Swiss federal railway operator (SBB). Managing Service Quality, 20(6), 511-530.

Giesbrecht, T., Schwabe, G., \& Schenk, B. (2017). Service encounter thinklets: How to empower service agents to put value co-creation into practice. Information Systems Journal, 27(2), 171-196.

Gilsing, R., Turetken, O., Adali, O. E., \& Grefen, P. A. (2018). Reference model for the design of service-dominant business models in the smart mobility domain. San Francisco: International Conference on Information Systems.

Gretzel, U., Sigala, M., Xiang, Z., \& Koo, C. (2015). Smart tourism: Foundations and developments. Electronic Markets, 25(3), 179188

Gupta, A., Deokar, A., Iyer, L., Sharda, R., \& Schrader, D. (2018). Big data \& analytics for societal impact: Recent research and trends. Information Systems Frontiers, 20, 185-194.

Gupta, B., Goul, M., \& Dinter, B. (2015). Business intelligence and big data in higher education: Status of a multi-year model curriculum development effort for business school undergraduates, MS graduates, and MBAs. Communications of the Association for Information Systems, 36.

Gupta, P., Chauhan, S., \& Jaiswal, M. P. (2019). Classification of smart city research - a descriptive literature review and future research agenda. Information Systems Frontiers, 21, 661-685.

Hasan, H., Smith, S., \& Finnegan, P. (2017). An activity theoretic analysis of the mediating role of information systems in tackling climate change adaptation. Information Systems Journal, 27(3), 271-308.

Hein, A., Scheiber, M., Böhm, M., Weking, J., Rocznik, D., \& Krcmar, H. (2018). Toward a design framework for service-platform ecosystems. Portsmouth: European Conference on Information Systems.

Hein, A., Weking, J., Schreieck, M., Wiesche, M., Böhm, M., \& Krcmar, H. (2019). Value co-creation practices in business-to-business platform ecosystems. Electronic Markets, 29(3), 503-518.

Hildebrandt, B., Hanelt, A., \& Firk, S. (2018). Sharing yet caring: Mitigating moral hazard in access-based consumption through ISenabled value co-capturing with consumers. Business \& Information Systems Engineering, 60(3), 227-241.
Jarzabkowski, P. (2003). Strategic practices: An activity theory perspective on continuity and change. Journal of Management Studies, 40(1), 23-55.

Kaptelinin, V. (1996). Computer-mediated activity: Functional organs in social and developmental contexts. In B. A. Nardi (Ed.), Context and consciousness: Activity theory and human-computer interaction (pp. 45-68). Cambridge: The MIT Press.

Karanasios, S., \& Allen, D. (2013). ICT for development in the context of the closure of Chernobyl nuclear power plant: An activity theory perspective. Information Systems Journal, 23(4), 287-306.

Karanasios, S., \& Allen, D. (2014). Mobile technology in mobile work: Contradictions and congruencies in activity systems. European Journal of Information Systems, 23(5), 529-542.

Karlsson, F., \& Wistrand, K. (2006). Combining method engineering with activity theory: Theoretical grounding of the method component concept. European Journal of Information Systems, 15(1), 82-90.

Klievink, B., Romijn, B.-J., Cunningham, S., \& de Bruijn, H. (2017). Big data in the public sector: Uncertainties and readiness. Information Systems Frontiers, 19, 267-283.

Kohtamäki, M., \& Rajala, R. (2016). Theory and practice of value cocreation in B2B systems. Industrial Marketing Management, 56, 4 13.

Korpela, M., Mursu, A., Soriyan, A., Eerola, A., Häkkinen, H., \& Toivanen, M. (2004). Information systems research and development by activity analysis and development: Dead horse or the next wave? In B. Kaplan, D. P. Truex III, D. Wastell, A. T. WoodHarper, \& J. I. DeGross (Eds.), Information systems research: Relevant theory and informed practice (pp. 453-471). New York: Kluwer Academic Publishers.

Koskela-Huotari, K., Edvardsson, B., Jonas, J. M., Sörhammar, D., \& Witell, L. (2016). Innovation in service ecosystems-Breaking, making, and maintaining institutionalized rules of resource integration. Journal of Business Research, 69(8), 2964-2971.

Kottow, M. H. (1986). Medical confidentiality: An intransigent and absolute obligation. Journal of Medical Ethics, 12(3), 117-122.

Kuutti, K. (1996). Activity theory as a potential framework for humancomputer interaction research. In B. A. Nardi (Ed.), Context and consciousness. Activity theory and human-computer interaction (pp. 17-44). London: Massachusetts Institute of Technology.

Leont'ev, A. N. (1978). Activity, consciousness, and personality Englewood Cliffs: Prentice-Hall.

Lusch, R. F., \& Nambisan, S. (2015). Service innovation: A servicedominant logic perspective. MIS Quarterly, 39(1), 155-175.

Malaurent, J., \& Karanasios, S. (2020). Learning from workaround practices: The challenge of enterprise system implementations in multinational corporations. Information Systems Journal, 30(4), 639663.

Mikalef, P., Pappas, I., Krogstie, J., \& Pavlou, P. (2020). Big data and business analytics: A research agenda for realizing business value. Information \& Management, 57(1), 103237.

Miles, M. B., Huberman, A. M., \& Saldaña, J. (2014). Qualitative data analysis: A methods sourcebook. Los Angeles: SAGE Publications.

Minkiewicz, J., Bridson, K., \& Evans, J. (2016). Co-production of service experiences: Insights from the cultural sector. Journal of Services Marketing, 30(7), 749-761.

Nueesch, R., Puschmann, T., \& Alt, R. (2014). Realizing value from tablet-supported customer advisory: Cases from the banking industry. Bled: Bled eConference.

Nunes, A. A., Galvão, T., \& e Cunha, J. F. (2014). Urban public transport service co-creation: Leveraging passenger's knowledge to enhance travel experience. Procedia - Social and Behavioral Sciences, 111(5), 577-585.

Okwechime, E., Duncan, P., \& Edgar, D. (2018). Big data and smart cities: A public sector organizational learning perspective. Information Systems and e-Business Management, 16, 601-625. 
Pappas, I. O., Mikalef, P., Giannakos, M. N., Krogstie, J., \& Lekakos, G. (2018). Big data and business analytics ecosystems: Paving the way towards digital transformation and sustainable societies. Information Systems and e-Business Management, 16(3), 479-491.

Payne, A. F., Storbacka, K., \& Frow, P. (2008). Managing the co-creation of value. Journal of the Academy of Marketing Science, 36(1), 8396.

Popovič, A., Hackney, R., Tassabehji, R., \& Castelli, M. (2018). The impact of big data analytics on firms' high value business performance. Information Systems Frontiers, 20(2), 209-222.

Pulkkinen, J., Jussila, J., Partanen, A., Trotskii, I., \& Laiho, A. (2019). Smart mobility: Services, platforms and ecosystems. Technology Innovation Management Review, 9(9), 15-25.

Rahman, M., Bose, S., Babu, M. M., Dey, B. L., Roy, S. K., \& Binsardi, B. (2019). Value co-creation as a dialectical process: Study in Bangladesh and indian province of West Bengal. Information Systems Frontiers, 21(3), 527-545.

Reinhardt, W. (2012). Öffentlicher Personennahverkehr: Technik rechtliche und betriebswirtschaftliche Grundlagen. Wiesbaden: Vieweg+Teubner Verlag.

Reypens, C., Lievens, A., \& Blazevic, V. (2016). Leveraging value in multi-stakeholder innovation networks: A process framework for value co-creation and capture. Industrial Marketing Management, $56,40-50$.

Schmidt-Rauch, S., \& Nussbaumer, P. (2011). Putting value co-creation into practice: A case for advisory support. European Conference on Information Systems: Helsinki.

Schreieck, M., Pflügler, C., Setzke, D. S., Wiesche, M., \& Krcmar, H. (2018). Improving urban transportation: An open platform for digital mobility services. In C. Linnhoff-Popien, R. Schneider, \& M. Zaddach (Eds.), Digital marketplaces unleashed (pp. 479-489). Berlin: Springer.

Schulz, T., Böhm, M., Gewald, H., Celik, Z., \& Krcmar, H. (2020). The negative effects of institutional logic multiplicity on service platforms in intermodal mobility ecosystems. Business \& Information Systems Engineering.

Schulz, T., Gewald, H., \& Böhm, M. (2018). The long and winding road to smart integration of door-to-door mobility services: An analysis of the hindering influence of intra-role conflicts. Portsmouth: European Conference on Information Systems.

Schulz, T., \& Überle, M. (2018). How institutional arrangements impede realization of smart ecosystems: The case of door-to-door mobility integrators. Portsmouth: European Conference on Information Systems.

Slavova, M., \& Karanasios, S. (2018). When institutional logics meet information and communication technologies: Examining hybrid information practices in Ghana's agriculture. Journal of the Association for Information Systems, 19(9), 775-812.

Storbacka, K., Brodie, R. J., Böhmann, T., Maglio, P. P., \& Nenonen, S. (2016). Actor engagement as a microfoundation for value co-creation. Journal of Business Research, 69(8), 3008-3017.

$\mathrm{Su}, \mathrm{N}$. (2013). Internationalization strategies of Chinese IT service suppliers. MIS Quarterly, 37(1), 175-200.

Sun, J. (2020). Ubiquitous computing capabilities and user-system interaction readiness: An activity perspective. Information Systems Frontiers, 22, 259-271.

Turetken, O., Grefen, P., Gilsing, R., \& Adali, O. E. (2019). Servicedominant business model design for digital innovation in smart mobility. Business \& Information Systems Engineering, 61(1), 9-29.

United Nations Department of Economic and Social Affairs (2015). World urbanization prospects.

Vargo, S. L., \& Lusch, R. F. (2004). Evolving to a new dominant logic for marketing. Journal of Marketing, 68(1), 1-17.

Vargo, S. L., \& Lusch, R. F. (2017). Service-dominant logic 2025. International Journal of Research in Marketing, 34(1), 46-67.
Vargo, S. L., Maglio, P. P., \& Akaka, M. A. (2008). On value and value co-creation: A service systems and service logic perspective. European Management Journal, 26(3), 145-152.

Verband Deutscher Verkehrsunternehmen (2018). 2017 Statistik.

Vygotsky, L. S. (1978). Mind in society: The development of higher psychological processes. Cambridge: Harvard University Press.

Watson, H. J. (2019). Update tutorial: Big data analytics: Concepts, technology, and applications. Communications of the Association for Information Systems, 44.

Watson, R. T., Boudreau, M.-C., \& Chen, A. J. (2010). Information systems and environmentally sustainable development: Energy informatics and new directions for the IS community. MIS Quarterly, 34(1), 23-38.

Watson, R. T., Boudreau, M.-C., Chen, A. J., \& Sepúlveda, H. H. (2011). Green projects: An information drives analysis of four cases. Journal of Strategic Information Systems, 20(1), 55-62.

Wikipedia (2016). Liste deutscher Tarif- und Verkehrsverbünde. https:// de.wikipedia.org/wiki/Liste_deutscher_Tarif-_und_Verkehrsverb\% C3\%BCnde. Accessed 2016-09-23.

Wilder, C. R., \& Ozgur, C. O. (2015). Business analytics curriculum for undergraduate majors. INFORMS Transactions on Education, $15(2), 180-187$.

Willing, C., Brandt, T., \& Neumann, D. (2017a). Electronic mobility market platforms - A review of the current state and applications of business analytics. Electronic Markets, 27(3), 267-282.

Willing, C., Brandt, T., \& Neumann, D. (2017b). Intermodal mobility. Business \& Information Systems Engineering, 59(3), 173-179.

Winkler, T. J., \& Wulf, J. (2019). Effectiveness of IT service management capability: Value co-creation and value facilitation mechanisms. Journal of Management Information Systems, 36(2), 639-675.

Winter, A., Alt, R., Ehmke, J., Haux, R., Ludwig, W., Mattfeld, D., Oberweis, A., \& Paech, B. (2012). Manifest-Kundeninduzierte Orchestrierung komplexer Dienstleistungen. Informatik-Spektrum, 35(6), 399-408.

Yin, J., Qian, L., \& Shen, J. (2019). From value co-creation to value codestruction? The case of dockless bike sharing in China. Transportation Research Part D: Transport and Environment, 71, $169-185$.

Yin, R. K. (2014). Case study research: Design and methods. Thousand Oaks: SAGE Publications.

Zhang, D., Zhou, L., Briggs, R. O., \& Nunamaker Jr., J. F. (2006). Instructional video in e-learning: Assessing the impact of interactive video on learning effectiveness. Information \& Management, 43(1), $15-27$.

Zott, C., \& Amit, R. (2009). Business model design: An activity system perspective. Long Range Planning, 43(2), 216-226.

Publisher's Note Springer Nature remains neutral with regard to jurisdictional claims in published maps and institutional affiliations.

Thomas Schulz is a $\mathrm{PhD}$ student at the Technical University of Munich (TUM), Germany, and works as a research associate at the Neu-Ulm University of Applied Sciences. He graduated in Management from University of Hohenheim, Stuttgart. His research focus is on service ecosystems, service platforms, and value co-creation in the mobility industry. His work has appeared in Business \& Information Systems Engineering, the European Conference on Information Systems (ECIS), the Pacific Asia Conference on Information Systems (PACIS), the American Conference on Information Systems (AMCIS), and the Hawaii International Conference on System Sciences (HICSS).

Dr. Heiko Gewald is Research Professor of Information Management at the Neu-Ulm University of Applied Sciences in Germany. He holds a Master degree in Business Administration from University of Bamberg, 
Germany, a European Master of Business Science from Heriot-Watt University Edinburgh, UK and a $\mathrm{PhD}$ in Information Systems from Goethe University Frankfurt. His research focuses on healthIT, the use of digital resources by the aging generation, and the digitization of the financial services industry. He is a frequent speaker on conferences contributing to these matters. His work has been published in the European Journal of Information Systems, Journal of Economic Commerce Research, Health Systems, Information \& Management, Information Systems Frontiers, Business \& Information Systems Engineering, Communications of the ACM and on numerous conferences.

Dr. Markus Böhm is research group leader at the Chair for Information Systems at Technical University of Munich (TUM), Germany. He graduated in Business \& Information Systems Engineering from FriedrichAlexander University Erlangen-Nürnberg (FAU), and holds a doctoral degree in Information Systems from TUM. Markus has a profound industry experience as project manager, analyst and software developer at among others fortiss, Siemens, Bosch and BMW. His research focus is on mergers \& acquisitions, business model innovation and digital transformation. Markus co-authored more than 100 research papers published in all major IS conference proceedings as well as IS, Informatics and Business Journals including Electronic Markets, MIS Quarterly Executive, the Journal of Systems and Software, the Journal of Business Economics and Business \& Information Systems Engineering.
Dr. Helmut Krcmar is Professor of Information Systems, Department of Informatics, at Technical University of Munich (TUM) with a joint appointment to the School of Management. His work experience includes a Post-Doctoral Fellowship, IBM Los Angeles Scientific Center, and Assistant Professor of Information Systems, Leonard Stern School of Business, NYU, and Baruch College, CUNY. From 1987 to 2002 he was Chair for Information Systems, University of Hohenheim, Stuttgart, where he served as Dean, Faculty of Business, Economics and Social Sciences. Helmut's research interests include information and knowledge management, engineering, piloting, and management of innovative IT-based services, computer support for collaboration in distributed and mobile work and learning processes. Helmut co-authored a plethora of research papers published in major IS journals including MIS Quarterly, Journal of Management Information Systems, Journal of Information Technology, Journal of Strategic Information Systems, Information Systems Journal, Information \& Management, Communications of the Association for Information Systems, ACM Transactions on Computer-Human Interaction and Business \& Information Systems Engineering. Interdisciplinary work incorporates areas such as accounting, mechanical engineering, and health care. Helmut collaborates in research with a wide range of leading global organizations. He is a Fellow of the Association of Information Systems (AIS) and member of acatech - National Academy of Science and Engineering. 